\title{
Operationalising coastal resilience to flood and erosion hazard: A demonstration for England
}

\author{
By I.H. Townend ${ }^{\text {a,* }}$, J.R. French ${ }^{\text {b }}$, R.J. Nicholls ${ }^{c}$, S. Brown ${ }^{\text {d }}$, S. Carpenter ${ }^{\text {e }}$, I.D. Haigh a , C.T. Hill e, E. Lazarus ${ }^{\text {e }}$, \\ E.C. Penning-Rowsell ${ }^{\mathrm{f}}$, C.E.L. Thompson ${ }^{\mathrm{g}}$, E.L. Tompkins ${ }^{\mathrm{e}}$ \\ a School of Ocean and Earth Science, University of Southampton, United Kingdom \\ b UCL Department of Geography, University College London, Gower Street, London WC1E 6BT, United Kingdom \\ c Tyndall Centre for Climate Change Research, University of East Anglia, Norwich NR4 7TJ, United Kingdom \\ d Department of Life and Environmental Sciences, Bournemouth University, United Kingdom \\ e School of Geography and Environmental Science, University of Southampton, United Kingdom \\ ${ }^{\mathrm{f}}$ Flood Hazard Research Centre, Middlesex University, United Kingdom \\ g Channel Coastal Observatory, National Oceanography Centre, Southampton, European Way, Empress Dock, Southampton SO14 3ZH, United Kingdom
}

\section{H I G H L I G H T S}

- Coastal resilience can be made operational to guide hazard policy and management.

- The Coastal Resilience Model (CRM) defines system state at both local and national scales.

- The CRM maps future socioenvironmental scenarios and projected adaptation pathways.

- The CRM captures stakeholder perspectives to inform resource allocation and policy making.

- An operational tool may need new data sets to be collected to fully describe resilience.

\section{A R T I C L E I N F O}

\section{Article history:}

Received 6 October 2020

Received in revised form 17 March 2021

Accepted 28 March 2021

Available online 5 April 2021

Editor: Martin Drews

\section{Keywords:}

Adaptation pathways

Policy

Management

Resilient communities

Socio-economic resource allocation

\section{G R A P H I C A L A B S T R AC T}

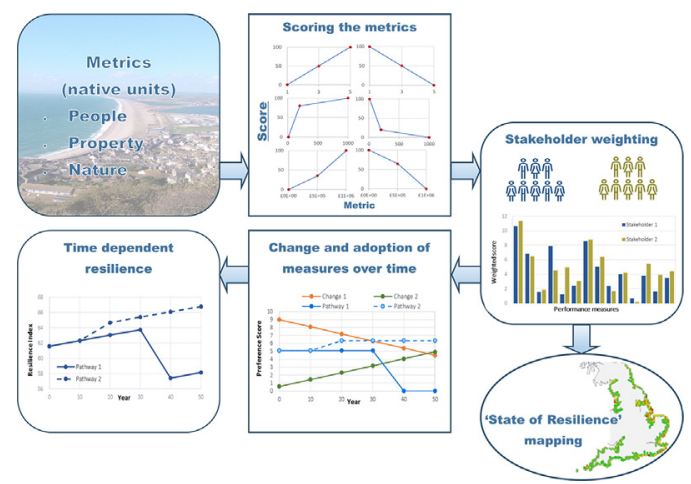

\begin{abstract}
A B S T R A C T
Resilience is widely seen as an important attribute of coastal systems and, as a concept, is increasingly prominent in policy documents. However, there are conflicting ideas on what constitutes resilience and its operationalisation as an overarching principle of coastal management remains limited. In this paper, we show how resilience to coastal flood and erosion hazard could be measured and applied within policy processes, using England as a case study. We define resilience pragmatically, integrating what is presently a disparate set of policy objectives for coastal areas. Our definition uses the concepts of resistance, recovery and adaptation, to consider how the economic, social and environmental dimensions of coastal systems respond to change. We develop a set of composite indicators for each dimension, grounded empirically with reference to national geospatial datasets. A prototype Coastal Resilience Model (CRM) has been developed, which combines the dimensions and generates a quantitative resilience index. We apply it to England's coastal hazard zone, capturing a range of different stakeholder perspectives using relative indicator weightings. The illustrative results demonstrate the practicality of formalising and quantifying resilience. To re-focus national policy around the stated desire of enhancing resilience to coastal flooding and erosion would require firm commitment from government to
\end{abstract}

* Corresponding author at: University of Southampton, School of Ocean and Earth Science, National Oceanography Centre, Southampton, European Way, Empress Dock, Southampton SO14 3ZH, United Kingdom.

E-mail address: i.townend@soton.ac.uk (B.I.H. Townend). 
monitor progress towards resilience, requiring extension of the present risk-based approach, and a consensus methodology in which multiple (and sometimes conflicting) stakeholder values are explicitly considered. Such a transition may also challenge existing governance arrangements at national and local levels, requiring incentives for coastal managers to engage with and apply this new approach, more departmental integration and inter-agency cooperation. The proposed Coastal Resilience Model, with the tools to support planning and measure progress, has the potential to help enable this transition.

(c) 2021 The Author(s). Published by Elsevier B.V. This is an open access article under the CC BY license (http:// creativecommons.org/licenses/by/4.0/).

\section{Introduction}

Resilience is widely viewed as an important attribute of natural systems (Holling, 1973; Pimm, 1991; Walker and Salt, 2006), including those at the coast (Klein et al., 1998; Bernhardt and Leslie, 2013; Masselink and Lazarus, 2019). In parallel it is starting to emerge as an overarching policy goal (Rosati et al., 2015; Sheaves et al., 2016). Examples include disaster management and emergency planning, as exemplified by the development of resilience-based coastal management programmes focusing on major disasters (Kim et al., 2014; USACE, 2014; Kress et al., 2016). Resilience is well established as a framework for managing socio-ecological systems (Paton et al., 2000; Adger et al., 2005) and is used to capture the complexity of climate change impacts on coupled ecological, geomorphic, socio-economic and engineered infrastructural systems (Park et al., 2013; Sheaves et al., 2016). However, operationalisation of resilience as a basis for strategic coastal management remains at an early stage of development.

The convoluted history of resilience as a concept (Alexander, 2013) has stimulated a lively academic discourse on inconsistencies in its definition (Klein et al., 2003; Haimes, 2009), the validity of some of the underlying assumptions regarding stability and equilibrium in ecological and geomorphic systems (Piégay et al., 2018; Masselink and Lazarus, 2019; Kombiadou et al., 2019), and their transferability from natural to human systems (Caffin and Scown, 2018). In this paper, we move beyond these debates to engage with the more pressing problem for coastal policymakers: how to quantify resilience in a way that is useful for strategic coastal management. Most analyses of coastal resilience have focused on a small number of state variables used to track the behaviour of specific ecological or geomorphic systems (e.g. French, 2006; Orford and Anthony, 2011; Houser et al., 2015; Chambers et al., 2019). Quantifying the resilience of complex systems that incorporate a multitude of physical, biotic, social and economic components and behaviours presents a greater challenge (Haimes, 2009). Using England as a case study, we demonstrate a practical method of measuring resilience for use in coastal management. Resilience, by nature of its focus on trade-offs within systems, incorporates a subjective element dependent on the goal or process that managers set. We show that this subjectivity can be turned into an advantage by using relative weightings (representative of different stakeholder perspectives) in a transparent way.

\section{Current coastal management in England}

In England, coastal erosion and flooding are major hazards (Masselink et al., 2020; Haigh et al., 2020) and a shoreline management approach was adopted to address these risks in the context of regionalscale coastal processes (Nicholls et al., 2013). Shoreline Management Plans (SMPs) are living documents that describe a small set of mutually exclusive high-level policy options for risk management within coastal management units, focusing on coastal defence. The options have evolved over time; the current set of options is: Hold the Line (maintain the present shoreline); No Active Intervention (take no further action to actively manage the coast); Managed Realignment (actively allow coastal retreat and often promoting the return of nature to coastal areas); and Advance the Line (actively move the current shoreline seaward).
In the 1990s, the first generation of 44 SMPs were produced for the coast of England and Wales. In a second iteration, these were consolidated to 22 SMPs covering the entire coast of England and Wales (Nicholls et al., 2013). The SMPs continue to be reviewed and updated, with the third and latest "refresh" ongoing at the time of writing to accommodate changes that have arisen since their production, and to consider: adaptation on dynamic and eroding coasts, links to land use planning (e.g., DEFRA, 2012, 2018), and the challenges this raises (e.g., Fisher and Goodliffe, 2020).

Climate change, particularly sea-level rise, is increasing the pressures at the coast and is already driving policy change. An investigation by the UK Committee for Climate Change (CCC, 2018) found that some coastal communities and infrastructure will almost certainly become unviable in their current form and that the policy options envisaged in the current SMPs will become unaffordable over current planning horizons. In particular, substantial lengths of coastal frontage will be undefendable at any reasonable cost and $71 \%$ of management units (accounting for $29 \%$ of the English coastline) with a policy of 'Hold the Line' will achieve a cost-benefit ratio well below the current funding threshold over this timescale. Major transitions in policy and practice are needed. One of the biggest challenges is to develop a strategy for these transitions that is affordable, sustainable, equitable and addresses societal pressures as well as natural system perturbations (Bostick et al., 2017).

Resilience as an overarching goal is increasingly prominent in English policy documents (notably DEFRA, 2015, 2018; HMG, 2016; EA, 2019). National policy statements on coastal resilience in England use inconsistent definitions, or none at all, and, as noted more generally by Pimm et al. (2019), have all the hallmarks of using resilience as an 'ideology' rather than a rigorous framework based on theory and quantitative evidence. A content analysis of recent policy documents for England (Supplementary Material S1 and Table S1) lends support to this view.

\section{Reframing resilience for coastal management: a pragmatic approach}

Like sustainability, resilience is an elusive concept, albeit one that is attractive to policymakers (Sidle et al., 2013; Fekete et al., 2019). Although resilience has often been conceptualised with reference to systems in a single domain (e.g. ecosystems or infrastructure systems), coastal resilience is a composite property that emerges from the interplay of diverse natural and human systems. There is also potentially an inherent conflict within any system, where a gain in resilience for some part(s) may result in a loss of resilience for others. In formulating our approach, we acknowledge that there can be no absolute notion of coastal resilience as it crosses diverse knowledge domains and traditions and objective single metrics are not possible (Haimes, 2009). Instead, we adopt a broad definition that encompasses some of the traditional elements of resilience, such as the ability of a system to rebound following a shock, as well as aspects of resistance that underpin risk-based coastal management (which emphasises protection against, or avoidance of, external flood and erosion hazards) and the capacity to both prepare and adapt. Other definitions are clearly possible, and there is much scope for variation in the detail. Working within a resilience paradigm, one seeks to maintain or improve the functionality of 
the system and this requires balancing social gains and losses, ideally through consideration of societal preferences (Adger, 2000; Kim and Marcouiller, 2020). Accordingly, we argue that it is not the precise definition that matters, but that a clear, pragmatic and consistent process is followed throughout an analysis, with clear metrics of system performance identified by stakeholders. Generic approaches based upon a shared understanding of resilience concepts are certainly valuable (Grafton et al., 2019). However, context is also important and it is essential that the conceptual definition adopted should be framed by the questions 'resilience against what?' and 'resilience for whom?'

For these reasons we adopt the US Army Corps of Engineers (USACE) definition (Rosati et al., 2015; USACE, 2014), this draws on recent work by Linkov et al., 2014 and Kress et al., 2016. This defines resilience as "the ability of a system to prepare, resist, recover, and adapt to disturbances in order to achieve successful functioning through time". In the context of coastal hazards, this draws upon the conceptualisation of resilience by Linkov et al. (2014) (Fig. 1a) as a cyclical sequence of actions catalysed by successive 'events'. This view of resilience incorporates the protective actions that have traditionally underpinned coastal engineering approaches to erosion and flood risk management (Thorne et al., 2007; Nicholls et al., 2013), as well as more dynamic adaptive responses to evolving hazards (Lawrence et al., 2019; Stephens et al., 2017; Ranger et al., 2013), and is therefore well-suited to our purpose. It is also important to stress that in this context 'events' can be acute shocks, as a result of large perturbations (such as major storms, hurricanes, or tsunami), or chronic stresses, as a result of gradual and more pervasive effects (such as sea-level rise/subsidence, progressive erosion, or saline intrusion). These may lead to a progressive loss of resilience over time, either because (i) relatively smaller 'events' result in failure, or a change of state, or (ii) capacity thresholds are passed, again leading to a change of state (e.g. the ecosystem services provided under different salinity regimes). As noted by Pimm et al. (2019) detecting such chronic stresses can be far more demanding to address than the more easily recognised acute shocks.

A recent contribution by Grafton et al. (2019) defines resilience as comprising resistance, recovery and robustness. These reflect a system's ability to simply adjust when perturbed, the time taken to recover a given functional state once perturbed, and the probability of a change in state (or crossing of a threshold) following one or more adverse events. In contrast, we argue that robustness is better characterised as a state change, which may occur if a system lacks sufficient resilience. Hence our view of resilience, when applied to complex coastal systems (natural + anthropogenic) is that it comprises resistance and recovery (as defined by Grafton et al) as direct responses to perturbations, but also preparation in anticipation of, and adaptation in response to, adverse events. This underpins our adoption of the definition by Rosati et al. (2015) given above.

Enhancing resilience in practice requires a transition from the present largely qualitative notion to a quantitative evidence-based framework (Pimm et al., 2019). As Cai et al. (2014) observe, a minority of disaster resilience studies are founded on quantitative measures, and only a subset of those attempt any empirical validation of such metrics. The coastal systems of interest here extend beyond individual geomorphological and ecological systems to a complex interplay between landform systems and their associated ecosystems, socio-economic systems and engineered infrastructural systems. The principal hazards are also compound in nature, dominated by flooding and erosion phenomena that interact, but also exhibit different spatial and temporal footprints. We thus must capture the state of a set of coupled sub-systems that are typically described in different ways and from fundamentally different perspectives. The challenge of how best to adapt to climate change and evolving hazards at the coast can thus be viewed as a 'wicked problem' in the sense of Rittel and Webber (1973) and Brown et al. (2014). Whilst this is already acknowledged in existing coastal management decision-making processes to some extent, it does greatly complicate the operationalisation of a quantitative resilience-based approach.

Returning to the questions concerning 'resilience against what' and 'for whom', we reason that the coast has a state of resilience that depends on a complex set of interactions. We do not seek, or need, to define this in any universally applicable sense. From a management, or policy, perspective a pragmatic approach is to identify those actions that will enhance resilience. To this end we define a set of generic coastal management objectives, which encapsulate actions that maximise the capacity to cope or minimise the potential for loss. The objectives we have used are summarised in Fig. 1b. Importantly, actions to maximise capacity, or minimise loss, can be used to address the different components of resilience, namely resistance, recovery and adaptation, either collectively or individually. Also note that there is no aim to maximise resilience, or achieve an optimum, because system constraints and trade-offs between different interests combine to make a)

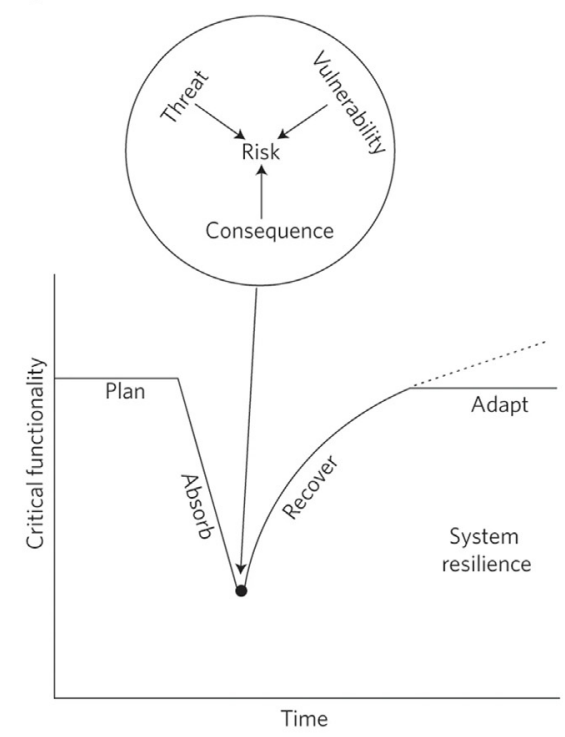

b)
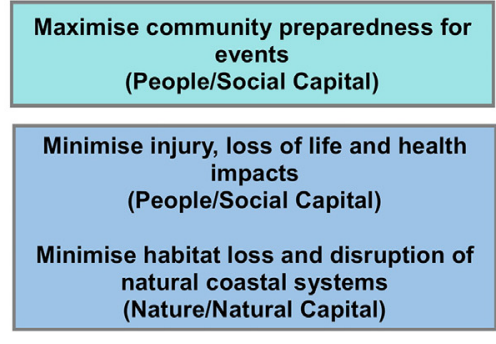

Minimise damage to property and infrastructure (Property/Physical Capital)

Minimise local economic disruption (Property/Physical Capital)

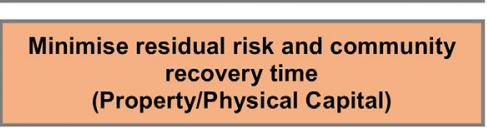

Maximise preparedness

$+$

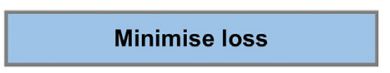

$+$

Minimise damage costs

$+$

Minimise risk and recovery

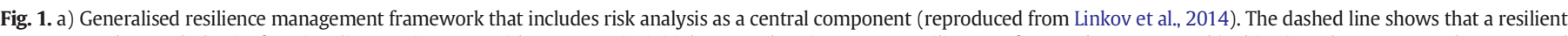

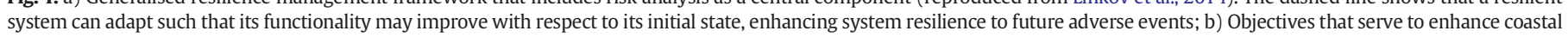
resilience by maximizing the capacity to cope and minimizing the potential for loss, subject to any local or national constraints. 
this a 'wicked problem', as noted above. As our context is coastal flooding and erosion, the objectives will have a different focus for these two forms of hazard, which characterise acute and chronic events, respectively. This translates into different measures to assess what is changing and appropriate responses for each type of hazard. For example, whilst an increased frequency of flooding may result in changes in land use, erosion implies a shift from a terrestrial to marine environment. Any framework to measure and use resilience to develop a policy response, therefore, needs to be flexible enough to address both chronic and acute hazards'.

Formal evaluations of coastal resilience have typically relied on expert elicitation as a way of achieving a scientific consensus based on knowledgeable opinions (e.g. Thorne et al., 2015; Sanderson et al., 2016). However, the growing availability of open geospatial datasets means that data-driven resilience assessments are now a practical possibility (Rumson and Hallett, 2019; Shamaskin et al., 2020). Numerous studies have already applied statistical analyses to multivariate measures of exposure and vulnerability that can be considered indicative of resilience within coastal communities (e.g. Hummel et al., 2018) and infrastructure (e.g. Brown et al., 2018). However, resilience is a broader concept than vulnerability and risk and, as Linkov et al. (2013) argue, must be analysed with bespoke methods that are complementary to, but also distinct from, those developed for risk analysis. Cross-disciplinary exchanges of ideas can be extremely valuable and Linkov et al. (2013) draw on military theory to map four dimensions of resilience (physical; informatic; cognitive; social) onto a four-stage event management cycle (plan/prepare; absorb; recover; adapt). Essentially the same conceptualisation has subsequently been adopted by the USACE (Rosati et al., 2015). The 'cells' of this $4 \times 4$ matrix guide the specification of individual resilience metrics and the whole matrix provides a transparent connection between resilience policies and likely outcomes (Linkov et al., 2013).

In contrast, our concept of resilience (Fig. 1b) is less tied to a disaster event management cycle but similarly defines an interface between the different dimensions of resilience ( social, economic and environmental) and key policy objectives that aim to enhance coastal resilience by maximizing the capacity to cope and minimizing the potential for loss. The next step is to operationalise this conceptual model of resilience and its associated policy options with a set of data-driven metrics. Multivariate geospatial datasets are already widely used in coastal vulnerability assessments (e.g. Ramieri et al., 2011; Christie et al., 2018), including those that explicitly cite resilience as a policy goal (e.g. Shamaskin et al., 2020). The extension of these analyses to encompass a wider range of resilience-related measures has become feasible with the growing availability of open datasets that provide insights into not just the geographical variation in hazards but also their consequences for coastal systems (Rumson et al., 2020).

\section{Operationalising the method}

Quantitative resilience-based coastal management offers many advantages over more narrowly focused risk-based analyses of vulnerabilities and likely losses (Linkov et al., 2014), but operationalising it to support coastal management encounters the problem of reconciling measures defined across the social, economic and environmental dimensions of the system. At one level, theoretical analyses imply that the overall resilience of complex and composite interacting systems subject to multiple, compounded, hazards is in principle unknowable (see, for example, Haimes, 2009). Recognising these challenges, we have pursued an approach that is grounded in current capabilities, whilst acknowledging the shortcomings and hence potential to develop the approach further.

To implement a framework for decision making, we adopt a method that is supported by a model to quantify the current state of coastal resilience and how this might change over time. We first outline the steps needed to establish the framework, before detailing the model developed to provide a quantification of the state of coastal resilience.

\subsection{Decision-making framework}

The initial steps in developing a policy or decision-making framework revolve around clarity of purpose, identification of the options available for implementation, and clear performance measures (DCLG, 2009; Willows and Connell, 2003). Therefore, the first steps needed to develop coastal resilience policies can be summarised as:

1. Establish the decision-making context (policy aims, decision-makers, key stakeholders).

2. Identify clear objectives that are specific, measurable, agreed, realistic and time dependent (i.e. SMART).

3. Define the available options that can realistically address the objective(s).

4. Design a method to evaluate likely outcomes and measure performance.

Similar steps underpin more recent methodological developments, such as dynamic adaptive policy pathways (e.g. Haasnoot et al., 2013; Stephens et al., 2018).

Our illustrative decision context is the management of coastal flood and erosion hazard in England. The starting point here is the wellestablished objectives used for SMPs. Historically, these have focussed on resistance measures and are intended to ensure the protection of people and property from flooding and coastal erosion, albeit with a range of supplementary concerns (e.g. relating to the environment and social deprivation). Whilst the focus remains on flooding and erosion, there is a need to consider objectives that consider more than protection or realignment of the shoreline. These objectives are presented in terms of system functions that need to be maximised or minimised in order to enhance resilience of the entire system in Table 1. Each high-level objective relates to one or more coast-specific objective, each of which may be elaborated with sub-objectives.

Our emerging coastal resilience framework is not a substitute for risk management but can be explicitly aligned with existing coastal risk management policy options and related governmental priorities. To do this, we develop policy options that seek to encapsulate the wider

Table 1

Summary of objectives and sub-objectives.

\begin{tabular}{|c|c|c|}
\hline $\begin{array}{l}\text { High level } \\
\text { agendas }\end{array}$ & $\begin{array}{l}\text { Coastal resilience } \\
\text { objectives }\end{array}$ & Sub-objectives \\
\hline Human health & $\begin{array}{l}\text { Maximise human } \\
\text { health }\end{array}$ & $\begin{array}{l}\text { Minimise (i) loss of life, (ii) injury, (iii) } \\
\text { health impacts }\end{array}$ \\
\hline Human assets & Minimise damage & $\begin{array}{l}\text { Minimise damage to (i) property and (ii) } \\
\text { infrastructure }\end{array}$ \\
\hline \multirow[t]{3}{*}{ Residual risk } & $\begin{array}{l}\text { Minimise response } \\
\text { time }\end{array}$ & - \\
\hline & $\begin{array}{l}\text { Minimise recovery } \\
\text { time }\end{array}$ & s \\
\hline & $\begin{array}{l}\text { Minimise } \\
\text { displacement }\end{array}$ & Minimise for (i) flooding and (ii) erosion \\
\hline Economy & $\begin{array}{l}\text { Minimise damage } \\
\text { to economy }\end{array}$ & $\begin{array}{l}\text { Minimise (i) local and (ii) national damage } \\
\text { (including supply chain impacts) }\end{array}$ \\
\hline \multirow[t]{2}{*}{ Natural assets } & $\begin{array}{l}\text { Minimise habitat } \\
\text { loss }\end{array}$ & - \\
\hline & $\begin{array}{l}\text { Minimise } \\
\text { disruption of } \\
\text { natural systems }\end{array}$ & - \\
\hline \multirow[t]{3}{*}{$\begin{array}{l}\text { Community } \\
\text { preparedness }\end{array}$} & $\begin{array}{l}\text { Maximise } \\
\text { preparedness }\end{array}$ & $\begin{array}{l}\text { Use (i) warnings and awareness, (ii) } \\
\text { monitoring and maintenance }\end{array}$ \\
\hline & $\begin{array}{l}\text { Minimise exposure } \\
\text { to risk }\end{array}$ & $\begin{array}{l}\text { Minimise exposure by (i) avoidance, (ii) } \\
\text { protection, (iii) limiting residual risk, and } \\
\text { (iv) limiting financial impact }\end{array}$ \\
\hline & $\begin{array}{l}\text { Maximise social } \\
\text { acceptance }\end{array}$ & - \\
\hline
\end{tabular}


Table 2

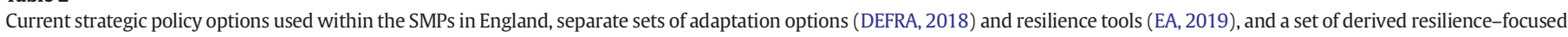
policy options that build on existing government agency activities.

\begin{tabular}{|c|c|c|c|}
\hline SMP policy option & Defra adaptation options & EA resilience tools & CoastalRes resilience policy options (applied in this paper) \\
\hline $\begin{array}{l}\text { - Hold the line } \\
\text { - Advance the line } \\
\text { - Managed realignment } \\
\text { - No active intervention }\end{array}$ & $\begin{array}{l}\text { - Preventing losses } \\
\text { - Tolerating losses } \\
\text { - Spreading or sharing losses } \\
\text { - Changing use or activity } \\
\text { - Changing location } \\
\text { - Restoration and replacement }\end{array}$ & $\begin{array}{l}\text { - Flood walls } \\
\text { - Coastal infrastructure } \\
\text { - Natural flood management } \\
\text { - Property flood resilience } \\
\text { - Flood forecasts and warning } \\
\text { - Sustainable drainage systems } \\
\text { - Evacuation } \\
\text { - Recovery } \\
\text { - Land management } \\
\text { - Spatial planning } \\
\text { - Innovation } \\
\text { - Moving people to new places }\end{array}$ & $\begin{array}{l}\text { - Land use planning } \\
\text { - Catchment management planning } \\
\text { - Coast protection (erosion and flooding) } \\
\text { - Flood and storm proofing } \\
\text { - Emergency planning } \\
\text { - Storm forecasting, monitoring and warning services } \\
\text { - Recovery and restoration } \\
\text { - Habitat creation (space for water) } \\
\text { - Socio-economic regeneration }\end{array}$ \\
\hline
\end{tabular}

scope required for adaptation. Table 2 summarises the current strategic policy options used for SMPs, and how these relate to a broader set of adaptation options (DEFRA, 2018) and resilience tools (EA, 2019), which are derived from work by Burton (1996) and Cimato and Mullan (2010). The Defra adaptation options are high level and generic but are generally consistent with the resilience principles defined in Fig. 1b. The EA resilience tools cover a mix of specific (e.g., flood walls) and vague (e.g., innovation) approaches. The final column of Table 2 presents a set of resilience-focused policy options produced by the UK National Environmental Research Council (NERC) funded 'CoastalRes' project (Townend et al., 2020) that is the focus of this paper. These policy options are intended to integrate the current SMP options into a set of non-mutually exclusive policy options that, taken together, could be used to deliver the enhanced coastal resilience that is envisaged by current policy statements (CCC, 2018; EA, 2019). Crucially, the resultant set of strategic policy options are all framed around existing, well established, government agency activities. We believe this is important to minimise the barriers to adoption. There is a need to be cognisant of the substantial investment in flood defences that has been made in many European countries, including the UK. Abandoning or decommissioning existing defences is an option that is likely to have little, if any, political traction over the short-term. A staged approach is more likely to achieve acceptance within communities and hence lead to political adoption. This will require exploration of the range of options available, including more radical solutions, such as transitions away from the coast over time.

\subsection{Quantification of coastal resilience}

The final step in the method outlined, step 4, involves the measurement of coastal resilience. This is needed to support planning, where likely outcomes need to be assessed, and during implementation, to measure ongoing performance. The focus is therefore on the state of the system at any point in time. This requires a conceptualisation of the system of interest in order to define relevant measures that contribute to the defined objectives (step 2). Integrating the various measures defines the present state of resilience, and projecting how the measures may change over time provides a forecast, or scenario testing, capability. This is the basic workflow used to establish the Coastal Resilience Model (CRM) (Fig. 2), as elaborated in more detail below. In essence, we map the multi-variate performance measures over the flood and erosion hazard zone and combine these measures to create a resilience index. This defines a state of the system. To evaluate changes in time we use scenarios to model the impact of external drivers (e.g. climate change, land use, etc.) and the likely response to selected policy options (e.g. emergency planning, socio-economic regeneration, etc.). The process of integrating the various performance measures entails a subjective weighting and we use this to incorporate different stakeholder perspectives and thereby provide a more nuanced characterisation of the state of resilience that reflects the inherent heterogeneity of societal perspectives.

Various approaches have been developed for the assimilation of inconsistently quantifiable multivariate data. Of these, Multiple Criteria

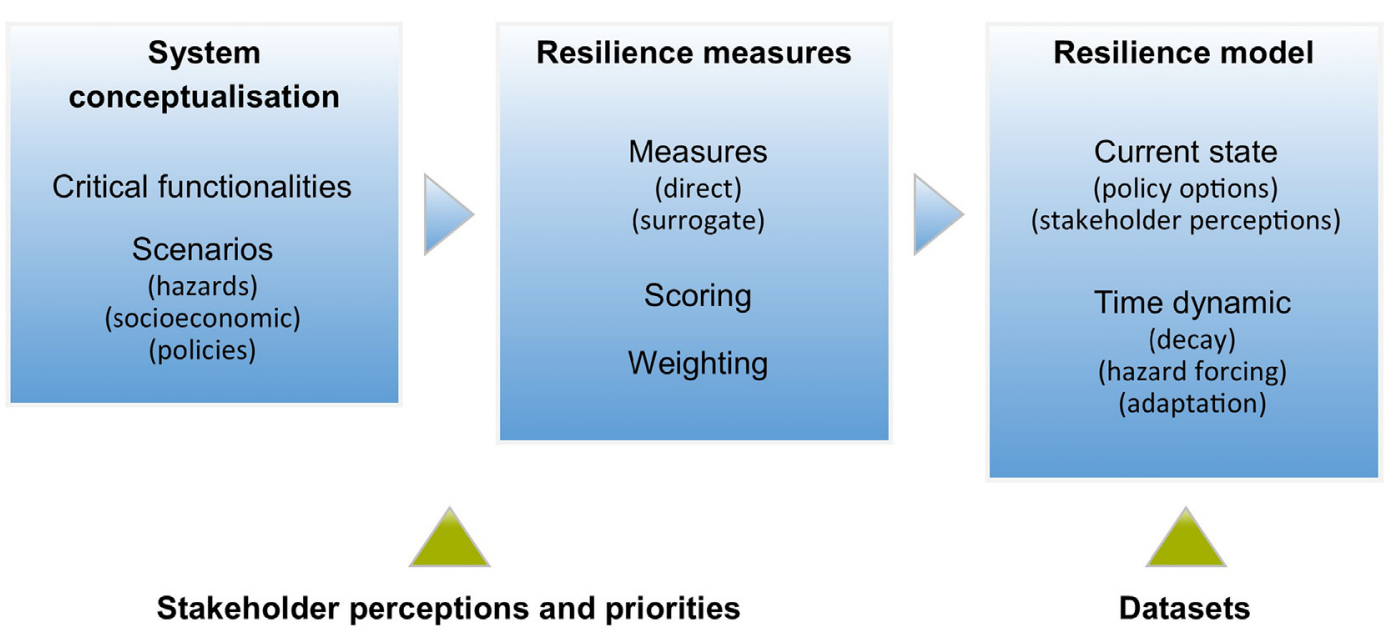

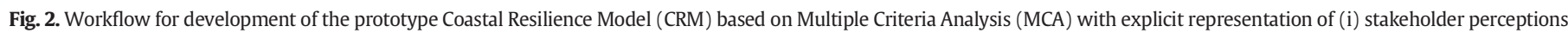
and priorities and (ii) timelines of change and pathways of adaptation. 
Analysis (MCA) (Keeney and Raiffa, 1976) has proved especially useful as a way of supporting decision-making processes by considering multiple and diverse criteria within a structured methodology. Various forms of MCA have been applied in areas such as coastal vulnerability assessment (Viavattene et al., 2018., Sekovski et al., 2020) and management of evolving flood risk (e.g. Brouwer and Van Ek, 2004; Levy, 2005; Ranger et al., 2013). MCA allows quantitative analysis of complex systems that are defined in terms of a set of variables, which may be measured in fundamentally different ways, including some that are only poorly quantifiable (Hajkowicz, 2008; Cinelli et al., 2014). It also provides an effective basis for incorporating stakeholder preferences into climate change adaptation strategies (e.g., Brown et al., 2001; Kim et al., 2017; Barquet and Cumiskey, 2018).

An MCA-based policy assessment typically involves defining the context, as described, and the following steps (DCLG, 2009):

(i) Identify criteria which measure progress towards the objectives, using performance measures which can characterise the current state and how this is likely to change.

(ii) Evaluate the provisional set of performance measures for, inter alia, completeness, redundancy, operability, independence, ability to resolve variation in performance over time, transparency and ease of communication to stakeholders.

(iii) Evaluate the performance of each option using the defined measures (e.g., with a performance matrix) via four sub-tasks:

a. Acquire the data needed to define each performance measure;

b. Apply scores and weights to reflect the relative importance of the performance measures;

c. Evaluate the ability of the approach to identify realistic options;

d. Apply sensitivity analysis to determine how different assumptions influence the outcome.

This is sufficient to characterise a static state. To extend the approach to dynamic systems, step (iii)a needs to be expanded to include data on future conditions such as climate change, demography, land use, etc. This will typically also require models that can capture the interaction between performance measures. Measuring the likely impact of one or more policy option similarly makes use of similar or additional data and models.

The range of measures and datasets that might conceivably relate to coastal resilience is large. For example, Rumson et al. (2020) list 254 candidate measures and data sources and pragmatic choices are necessary. Our conceptualisation of resilience (Fig. 1b) naturally unpacks into sub-sets of measures that relate to the social, economic and environmental dimensions of the system. Fig. 3 presents a conceptual diagram that relates these facets of resilience to an illustrative suite of measures that either directly or indirectly relate to the various minimisation or maximisation objectives in Fig. 1b. We acknowledge that subjective judgement is inevitably involved in the derivation of a composite resilience measure for a well-defined purpose and other conceptualisations are possible.

Some aspects of resilience, such as loss of life or certain economic damage costs, can be evidenced via direct measures. Others, such as those relating to the capacity for recovery following a hazard event, can presently only be approximated by surrogate or proxy measures (e.g., using a selected deprivation index). Surprisingly, there is no complete and consistently compiled national flood defence infrastructure dataset, or high spatial resolution data on insurance cover. Further details of the geospatial datasets used in the analysis presented below and the data processing workflow are provided in Carpenter and Hill (2020).

In our model to quantify coastal resilience, step (iii) is completed to determine the current state of the system, which includes geographical variation in resilience. From this baseline, time variations of key drivers (demography, sea level and storminess, national/international policy context, etc.) can be introduced to establish a set of future scenarios. Sets of policy options defined for each hazard zone may also include transitions between options and multiple pathways for adaptation (see also Ranger et al., 2013). Such transitions may well be linked to thresholds or trigger points, rather than being imposed at some fixed point in time. Quantification of the time evolution of overall coastal system resilience in this way provides a powerful approach for time-

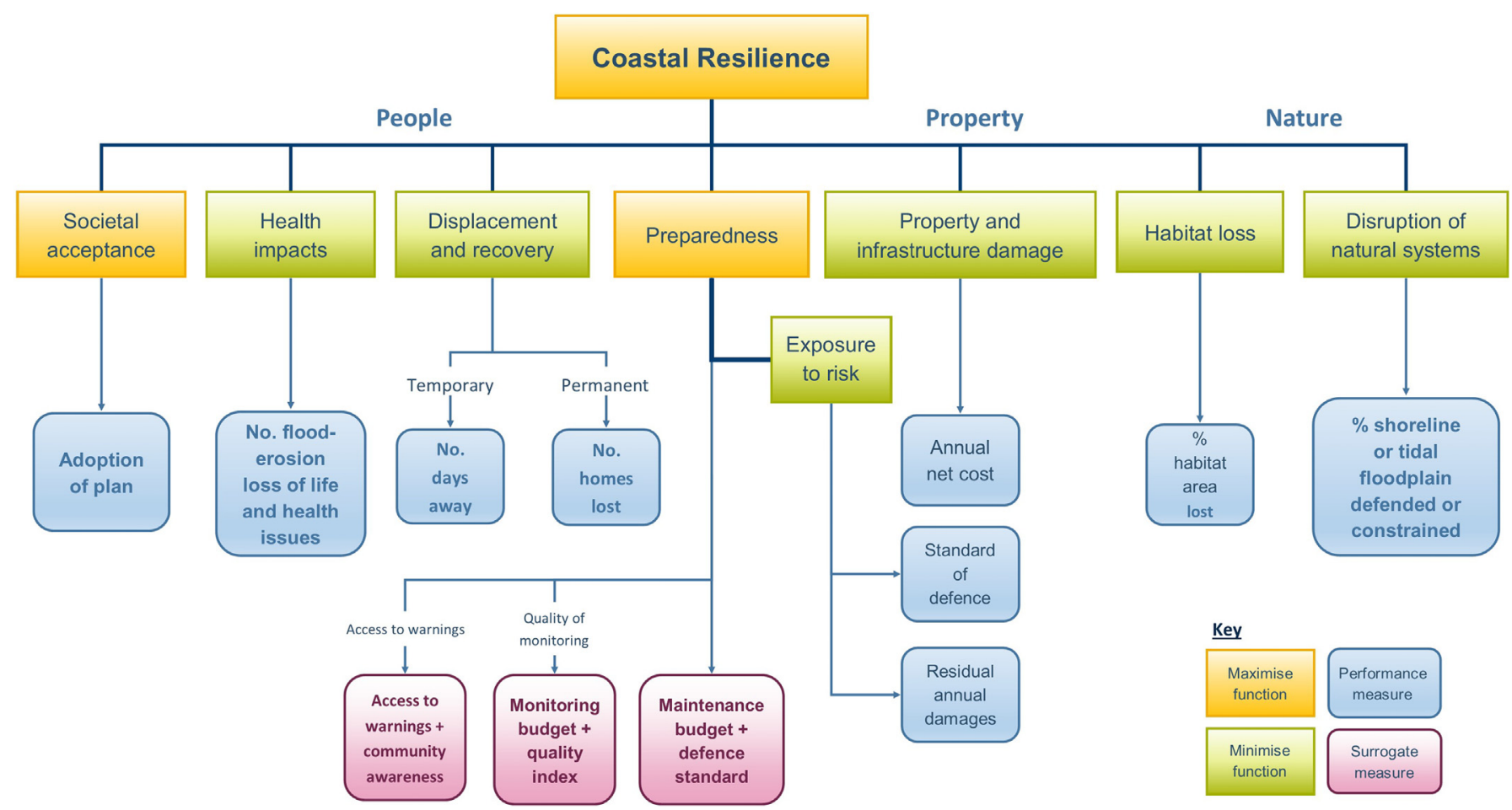

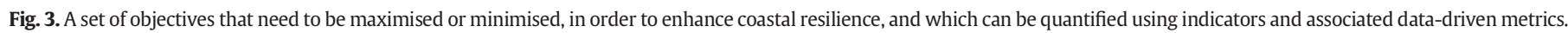
People, Property and Nature refer to the social, economic and environmental dimensions of the system. 
dependent decision management (Ranger et al., 2013; Stephens et al., 2018; Haasnoot et al., 2018) given the deep uncertainty that inevitably surrounds our understanding of future hazards (Walker et al., 2013; Marchau et al., 2019).

We implemented an MCA-based determination of overall system resilience based on a suite of performance and component metrics, which were determined for areal units representing combined flood and erosion hazard zones. The basic workflow is summarised in Fig. 2. First, each of the data-driven metrics was transformed to a common scale ( 0 to 100 ) to give a set of metric scores (s). Appropriate transformations range from simple linear functions, to non-linear or more complex (e.g., sigmoidal) functions, and these may be either positive or negative (according to whether the goal is to minimise or maximise the metric). For simplicity, we use two-part linear functions. Performance measures are typically defined from multiple metrics. This necessitates a twostage process in which each of the broader performance measures $\left(P_{j}, j=1 \ldots N\right)$ are defined by the weighted combination of their constituent metric scores $\left(s_{i}, i=1 \ldots M\right)$. Thus:

$P_{j}=\sum_{i=1}^{M} q_{i} s_{i}$

where $\mathrm{q}_{\mathrm{i}}, \mathrm{i}=1 \ldots \mathrm{m}$ are weights assigned to the metric scores that combine to give $\mathrm{P}_{\mathrm{j}}$, where

$\sum_{i=1}^{M} q_{i}=1$

A composite Resilience Index $(R I)$, is then obtained as

$R I=\sum_{j=1}^{N} w_{j} P_{j}$

where $w_{j}, j=1 \ldots N$ are weights assigned to the performance measures. We found it more intuitive to define this second set of weights on a scale of 0 to 100 and then to convert them to a scale of 0 to 1 , such that

$\sum_{j=1}^{N} w_{j}=1$

The two sets of weights introduce subjective judgement to the process in that different sets of experts, stakeholders or decision makers are likely to assign values that reflect personal knowledge, perceptions and priorities. This has sometimes been highlighted as an inherent weakness of MCA (Garmendia et al., 2010; Estévez and Gelcich, 2015). However, in the context of resilience this subjective aspect encapsulates the variation in human values and views. This can be used advantageously to capture the knowledge and preferences of distinct stakeholder groups in a way that allows the effect of these on perceived resilience outcomes to be presented and communicated in a transparent way (Raymond et al., 2010). There are a range of formal methods for eliciting the preferences of stakeholders and decision makers, such as Deliberative Mapping (Burgess et al., 2007) and Analytic Hierarchy Process (ATP) (Saaty, 1980): ATP involves a pairwise comparison between every pair of options (Roy, 1968). We utilise weightings derived using a simple hierarchical ranking process. To simulate a stakeholder elicitation, the project team adopted different economic, social and environmental perspectives (Townend et al., 2020).

For operational use, any RI needs to be able to evaluate how the current state may vary over time (a) due to external drivers (e.g. climate change, land use etc.) and (b) in response to the implementation of one or more policy options (e.g. emergency planning, socio-economic regeneration etc.). To do this, we first define one or more scenarios to describe how conditions may change in the future. We then define a set of policy pathways. These set out how the various policy options might be used. Some options might be applied for the entire simulation period, whereas others may introduce changes either at a given time, or in response to triggers defined within an adaptive management framework (e.g., Ranger et al., 2013; Lumbroso and Ramsbottom, 2018; Hall et al., 2019; Kingsborough et al., 2016). In other fields, these approaches have been labelled Real Options Analysis (ROA), Dynamic Adaptive Pathway Planning (DAPP), Decision Making Under Deep Uncertainty, but are essentially applying the same concepts (e.g., Lawrence et al., 2019; Haasnoot et al., 2013; Marchau et al., 2019).

\section{Illustrative local-scale studies}

As a demonstration of our approach, we first present an illustrative analysis using the CRM for the City of Portsmouth, supplemented with consideration of the rural north bank of the Outer Humber Estuary, east of Kingston-upon-Hull (Fig. 5). We select these sites because they are both highly exposed to coastal hazards and yet represent contrasting urban and rural settings which test our resilience measures. First, we assess the current state of resilience (Fig. 4) at a local scale. We then consider how resilience might evolve over time using scenario analysis. It is emphasised that these worked examples are illustrative demonstrations of the CRM; they would require further development for policy application and the insights reflect the method and approach rather than the outputs per se. Furthermore, whilst we examine two future scenarios, the number of "futures" and "pathways" considered is only limited by data availability, time and resources.

Portsmouth combines urban estuary and open coast settings and is one of the most densely populated cities in England, with an historic core and more recent expansion (Stevens et al., 2015). It includes an important commercial port and an historic naval dockyard. Portsea Island is surrounded by the diverse and biologically rich coastal and marine environments of Portsmouth Harbour, Langstone Harbour and the Solent, including internationally designated habitats and species (Cope et al., 2007). The city has many heritage assets, including several Scheduled Ancient Monuments. The city is low-lying and Wadey et al. (2012) estimate that more than 14,000 properties are situated in the 1 in 200year coastal flood plain. Coastal flooding during storms and high tides is a regular threat and this is being enhanced by sea-level rise (Haigh et al., 2011). As a result, a substantial proportion of the defences at Portsmouth are being upgraded including an allowance for sea-level rise. Whilst this greatly reduces the risk of flooding, residual risk in the unlikely event of failure must still be considered, as in all flood prone areas.

In contrast, the north bank of the Outer Humber Estuary is an extensive low-lying area of rural land, which was claimed from the estuary by enclosure several hundred years ago. The area is predominantly fertile agricultural land but is now lower than the highest tides because it no longer receives sediment from the estuary. Until recently the entire area was defended with embankments but short lengths of defence are now being removed to create new wetland areas and, thereby, offset intertidal losses due to coastal squeeze elsewhere in the estuary (Winn et al., 2003; Turner et al., 2007). There is a small rural community and the area to seaward of the defences is ecologically important and protected under several conservation designations.

First, we focus on Portsmouth. The current status of the performance measures for Portsmouth is illustrated in Fig. 6. These vary significantly according to the simulated stakeholder weightings derived to illustrate the different overarching perspectives (Fig. 6). The measures sum to give the $R I$ values shown. The different values reflect the different weightings, such as a social perspective putting more weight on human health, response time, recovery time, possible displacement of people, warnings and evacuation and insurance. In contrast, the economic perspective emphasises the avoidance of damage to assets and economy, and the environmental perspective prioritises coastal habitat and, perhaps surprisingly, social acceptance.

Looking to the future, resilience will evolve over time depending on a range of factors, including policy choices. To illustrate how the CRM 


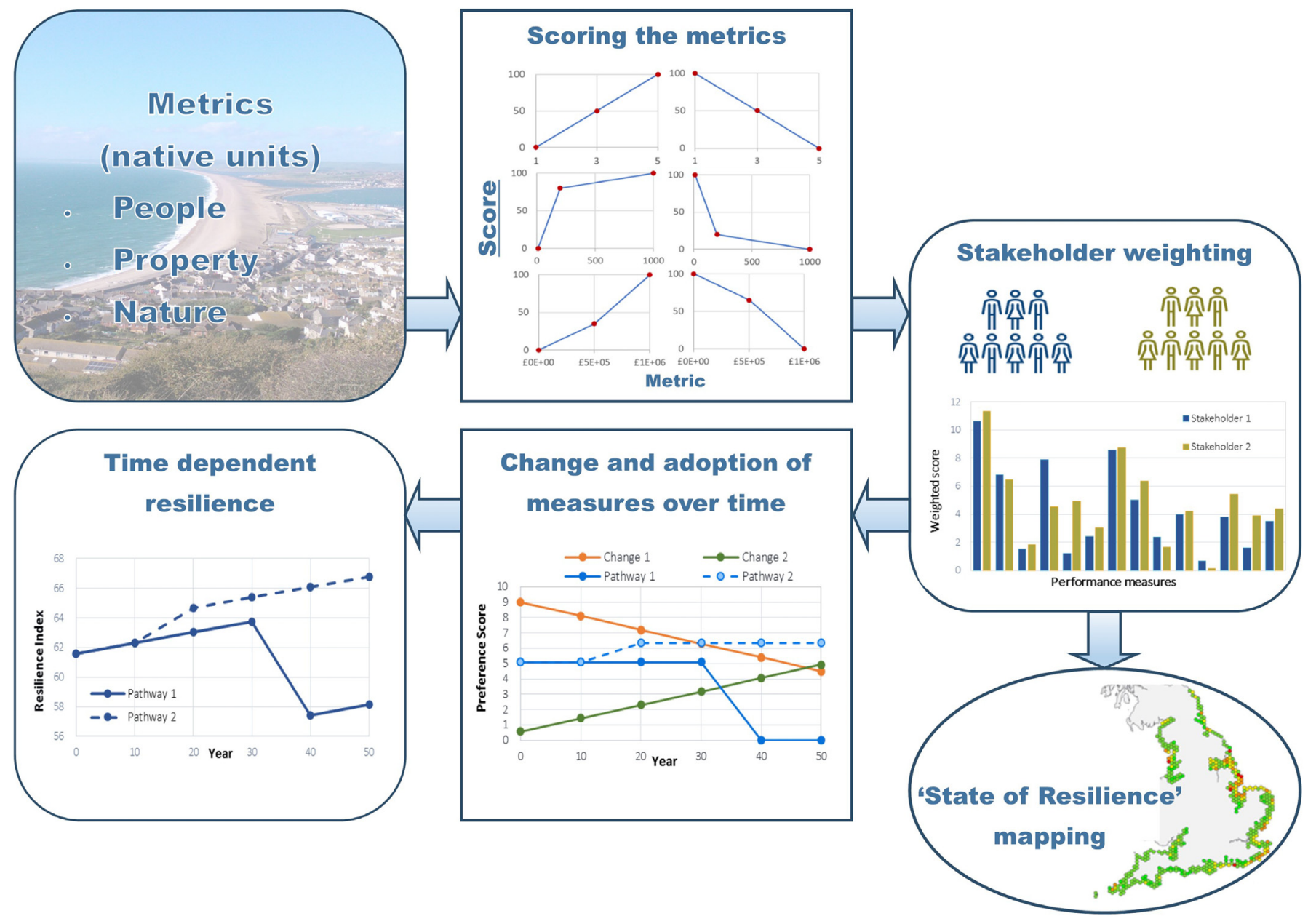

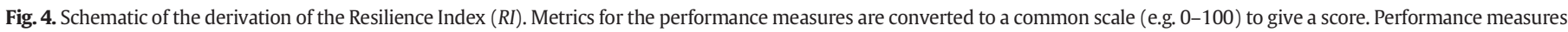

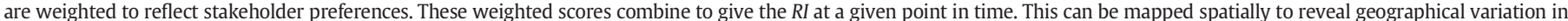

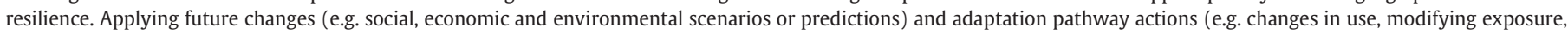
relocation, education, etc.), generates a timeline for each performance measure. Summing the time dependent preference scores gives a timeline of the RI for each projected pathway.

can analyse this, we consider two stylised pathways of how resilience might evolve over a 50-year period in Portsmouth. Pathway 1 (P1) assumes decline in defence standard due to sea-level rise, thereby increasing the residual risk over time. Pathway 2 (P2) assumes upgrading of emergency services and response plans, increasing public awareness and improving the provision of flood proofing over time.

The performance measures under the two pathways show a clear difference after 50 years under all three stakeholder perspectives and the combined viewpoint (Fig. 7a and b). The RI is higher under P2 than P1 under all perspectives. This type of plot provides a "signature" of the resilience state that enables inter-comparison of different perspectives, times in the projection and sites (although the latter needs particular caution because of the influence of local conditions). These resilience signatures (Figs. 6 and 7) are a key aid when interpreting both the degree and the nature of resilience, both locally and nationally. As such, they could enable constructive dialogue with stakeholders on the selection of policy pathways.

As well as snapshots, the evolution of RI over time under the two pathways can be assessed (Fig. 8). The distinction between the three perspectives for $R I$ is again highlighted, as is the marked difference in outcome after 50 years between the pathways, regardless of the stakeholder perspective that is considered. The evolution of performance measure under P1 and P2 is shown in Fig. 9a and b, respectively. In these illustrative analyses, the future scenario and policy response pathway influence on the performance measures was modelled simply using linear trends or step changes, as appropriate. Hence, the temporal changes in Fig. 9 are predominantly positive or negative linear trends. With further development, and more complex models to better capture feedbacks between the forcing conditions, policy actions and the measures themselves, a more nuanced picture should emerge.

The results for this case study are sensitive to the social, economic, or environmental weighting of decision makers. The RI values for the economic and social perspectives are quite similar at the start of the simulation period but diverge over time for both pathways. In contrast, the environmental perspective weightings suggest a much lower resilience. The level of exposure and the potential to enhance community awareness and responsiveness results in an improved resilience compared to Pathway 1, which shows a progressive decline as the effect of climate change reduces the standard of defence. This in turn increases the residual risk due to the high population and asset base within the flood hazard zone.

Fig. 10 maps the $R I$ for each stakeholder perspective and the combined index for the Portsmouth and Humber case studies, respectively. This indicates the scale of analysis. There is a large variation in resilience across Portsmouth, with consistently high values at some sites such as Farlington, and lower values in some areas such as parts of Southsea. This reflects high economic exposure to hazard and the resulting residual risk despite a high level of protection from defences. This reduces $R I$ from the economic perspective. Low resilience indices under the environmental perspective for areas in the centre of Portsmouth reflects a lack of habitat areas. The North Humber has a similar overall RI to Portsmouth, but the components differ. The extensive habitats to seaward of 
the defences contribute to higher RI values from an environmental perspective. However, economic and social resilience are lower than Portsmouth. 'Response Time' measured with emergency service data is lower than Portsmouth. This highlights how rural areas may be less well served by emergency services and so have a lower social resilience. The presence of various strategic infrastructure points, local wind turbines, and some 'properties' reduce its economic resilience. Aspects of the method also influence the results. For example, property density is enhanced because farms typically comprise multiple buildings. Such detailed analysis across all the diverse components of resilience shown in Fig. 3 for both these study regions provide interesting new insights about the regions and raise detailed questions on further development of the methodology towards policy application.

\section{National analysis: applying the Coastal Resilience Model (CRM) in England}

The MCA-based approach adopted in the Coastal Resilience Model (CRM) presented above can, in principle, be applied at any scale for which data are available, and a core goal was the development of an analytical approach that can be applied across multiple scales. Given the challenges of adapting to climate change at the coast (CCC, 2018; Oppenheimer et al., 2019) it is of particular interest to understand how geographic variations in resilience to coastal flooding and erosion might have a bearing on decision-making at a national scale. Accordingly, the same analytical workflow used in the Portsmouth and Outer Humber Estuary (North Bank) case studies was used to explore variation in the Resilience Index around the entire coast of England. Again, it is emphasised that this is a purely illustrative proof of concept exercise at this stage. Accordingly, the current state of resilience was modelled using the same set of weightings defined from the simulated elicitations of economic, social and environmental perspectives that were used to conduct the local case studies. Further consideration of this national analysis and its implications for measuring coastal resilience is reported elsewhere (Nicholls et al., in prep).

A considerable amount of geospatial data processing is involved in an analysis at this scale and the first task was to segment the coast into appropriate spatial units. Consideration was given to the use of existing SMP Shoreline Management Units. However, these are primarily defined by classifying the coast according to the hazard experienced, the urban or rural characteristics of the hinterland, and the status of the existing defences. This neglects broader social, economic and environmental aspects (Gerard, 2017) as well as the compound nature of the hazard in many locations. It was therefore necessary to construct an integrated hazard zone defined by a shoreline and erosion and flood extent datasets with an analysis layer constructed around spatial data Output Areas (OAs). These OAs typically contain less than 150 individual households and are the smallest unit of census reporting in the UK (ONS, 2012). The national data sources for the erosion and flood hazard zones are summarised in Carpenter and Hill (2020).

Application of the CRM algorithms to the geospatial datasets was undertaken for a total of 8382 OAs within the combined coastal flood and erosion hazard zone. The raw output at this level includes small and narrow zones along the coastline, which are difficult to visualise at a national scale. Accordingly, aggregation to larger regularly-shaped areal units was used to achieve more effective visual representation. Hexagons were used to reduce sampling bias (Sahr et al., 2003) and to represent the irregular coastline without producing gaps within the data. After some experimentation, a hexagon area of $90 \mathrm{~km}^{2}$ was selected. An arithmetic mean $R I$ value was determined from every $\mathrm{OA}$ within a given hexagon.

The RI takes similar values at a national scale to those observed in local case studies, although differences can be expected due to the aggregation from the 'native' OAs to the larger output hexagons used at the national scale. Nationally, the index has a mean of 66 with a minimum and maximum of 33.1 and 88.2 (from a possible range of 0 to
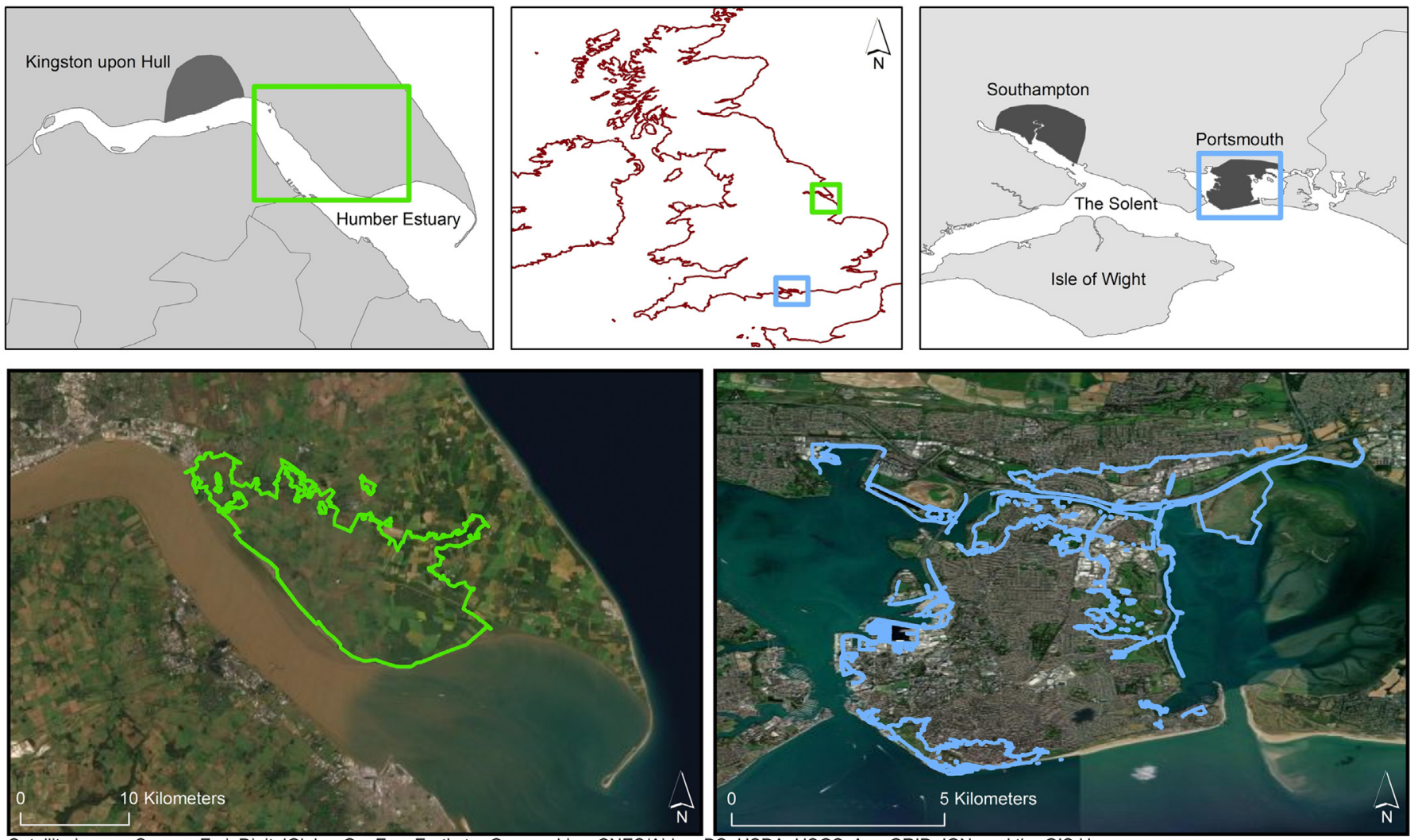

Satellite images Source: Esri, DigitalGlobe, GeoEye, Earthstar Geographics, CNES/Airbus DS, USDA, USGS, AeroGRID, IGN, and the GIS User

Fig. 5. Location of Portsmouth and Humber case studies. The erosion and flood prone areas analysed are indicated. 


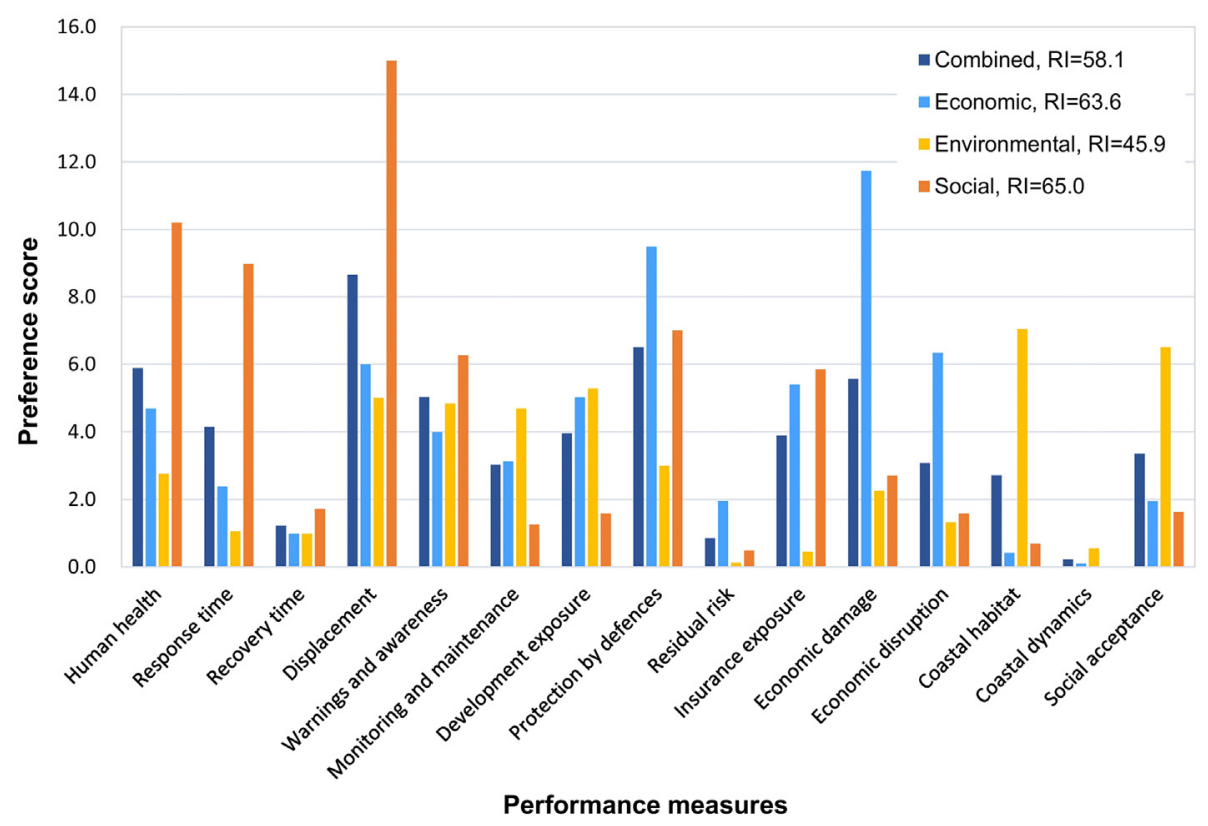

Fig. 6. Current preference scores for Portsmouth using weights allocated according to social, economic and environmental perspectives, and the combined perspective.

100). The distribution is unimodal with a slight negative skew (Fig. 11 (b)). A preliminary map of the combined coastal resilience index (i.e., averaging across the distinct economic, social and environmental perspectives) for England is shown in Fig. 11 (a). It is notable that the southwest England appears comparatively resilient, whereas the east and southeast are more varied, with lower resilience scores that are well below the mean. These highlight coastal towns as well as stretches of coast with more rapid erosion or greater vulnerability to flooding. Coastal towns with higher levels of deprivation also stand out in the northwest.

To operationally implement the CRM at a national scale, will require (i) a set of metrics to be agreed; (ii) the relevant data sets and scenarios to be established; (iii) processing capacity; and (iv) dialogue between agencies and stakeholders. Whilst this will require proactive commitment by policy makers and the relevant agencies, this pilot project has demonstrated that a national analysis of resilience is achievable (the pilot was completed in under a year).

\section{Discussion}

In this paper, we present a decision-making framework and a new Coastal Resilience Model that measures resilience as a composite property of a set of coupled natural, social and economic coastal subsystems. We opted to use the MCA methodology as it is wellestablished, but are aware that the method has its critics, particularly regarding the subjective nature of scoring and weighting. As already noted, there are a range of methods for eliciting the preferences of stakeholders and decision makers, such as Deliberative Mapping (Burgess et al., 2007) and the Analytic Hierarchy Process (Saaty, 1980) that formalise the development of scoring functions and weightings. We see the development of these methods in partnership with stakeholders as a way of making the, hitherto hidden, divergence of views and resulting scores explicit and debatable. This turns a perceived weakness of the MCA method into a strength and the resulting understanding of stakeholder views and preferences is essential for the successful operationalisation of resilience in the way we have advocated in this paper.

To illustrate the method, we decided to explore how existing policies, regulatory frameworks and management practices could be adapted to meet the overarching objective of enhancing coastal resilience. This link to present policy facilitates the initial adoption of the
CRM approach, but, once adopted, CRM will start to influence and change policy, regulation and management practise. Our use of MCA, whilst fundamentally data-driven, also uses the explicit representation of stakeholder perspectives to develop a more nuanced understanding of the options and their likely impact (see also Bostick et al., 2017). Comparing the results for different stakeholder perspectives over multiple scales - from local management unit to national analysis - adds an important dimension that can support the decision-making process. Recognising that societal priorities and policies change over time, the ability to include scenarios based on prevailing paradigms and then update them to reflect changing stakeholder preferences ensures that the CRM can evolve and remain relevant over time (Shaxson, 2005). The generic method used in the CRM is flexible, can be applied using different combinations of resilience metrics and/or data sources, and could be adapted to address the specific needs of different countries, as well as diverse policy goals and contexts.

There are two limitations of the CRM as outlined that are worth highlighting. These relate to data and scenarios or projections of the future. Data are essential to quantify the current state of the performance measures and how the state changes over time. Our experience was that marrying data sets that are currently available with specific performance measures was challenging. Even after several iterations, our choice of metrics remains sub-optimal and would benefit from further development. This includes enhancement of national coastal datasets (Carpenter and Hill, 2020; Lazarus et al., 2020). In addition, future projections (or scenarios) require an understanding of what is changing, both within the system and externally, that can alter the state of the system. However, modelling the implications of known environmental and especially social change (e.g., changing demographics) is difficult (Le Cozannet et al., 2015; Sanuy et al., 2020). Superimposing the additional changes that arise from planned interventions adds to this complexity. Here we took a simple approach, considering only linear and stepped changes of the performance measures in response to changing conditions, and using subjective assessment to define the interaction between measures and the implications of potential feedback loops. Developing this prognosis dimension to the CRM requires a more sophisticated modelling approach to the system dynamics, ideally coupled to improved monitoring and decision-making approaches targeted at identifying key triggers (Haasnoot et al., 2018; Stephens et al., 2018; Pimm et al., 2019). The need to address the interactions across the physical-biological-socialeconomic sub-systems makes both identifying suitable metrics and 
representing them in any scenario-pathway model particularly challenging and, hence, is an aspect that merits further research.

Mapping the current state of resilience provides a snapshot and relies on historic records. This, of itself, is useful to identify where resilience is low, but is unlikely to differ dramatically from previous riskbased analyses, although the different economic, environmental and social perspectives can be illuminating. Beyond this, CRM offers important benefits as a forward planning tool. By providing a formal framework to engage with stakeholders and capture their views in an explicit resilience statement - the "resilience signature" - the CRM can be used to establish a dialogue. Some decisions may need to be based on the available information, whilst others may be better deferred until more information is available, as now routinely adopted in the strategic planning of major infrastructure (Ranger et al., 2013; Lumbroso and Ramsbottom, 2018; Hall et al., 2019; Kingsborough et al., 2016). However, management decisions must often be made based on the information available at a given time. Incorporating adaptive pathways in the management approach, increases the potential for a more flexible response. This also implies that as opportunities and decisions are updated over time, assessments can consider new information and understanding related to ongoing environmental and societal change and also any changes in societal preferences (by updating the CRM weightings).

Policy pathways are predicated on local knowledge which will need to be developed with stakeholders. If these were developed alongside integrated models and relevant scenarios, the state of resilience can be examined over time, as illustrated by the results presented. A national appraisal could then consider different resource allocation models (e.g. economic benefit, social wellbeing, environmental gain, etc.) to explore how different policy choices impact the overall state of resilience at a national scale and the implications of these choices at a local scale. This would provide a sound basis for policy guidance to inform local decision making and the refinement of policy pathways.

a)

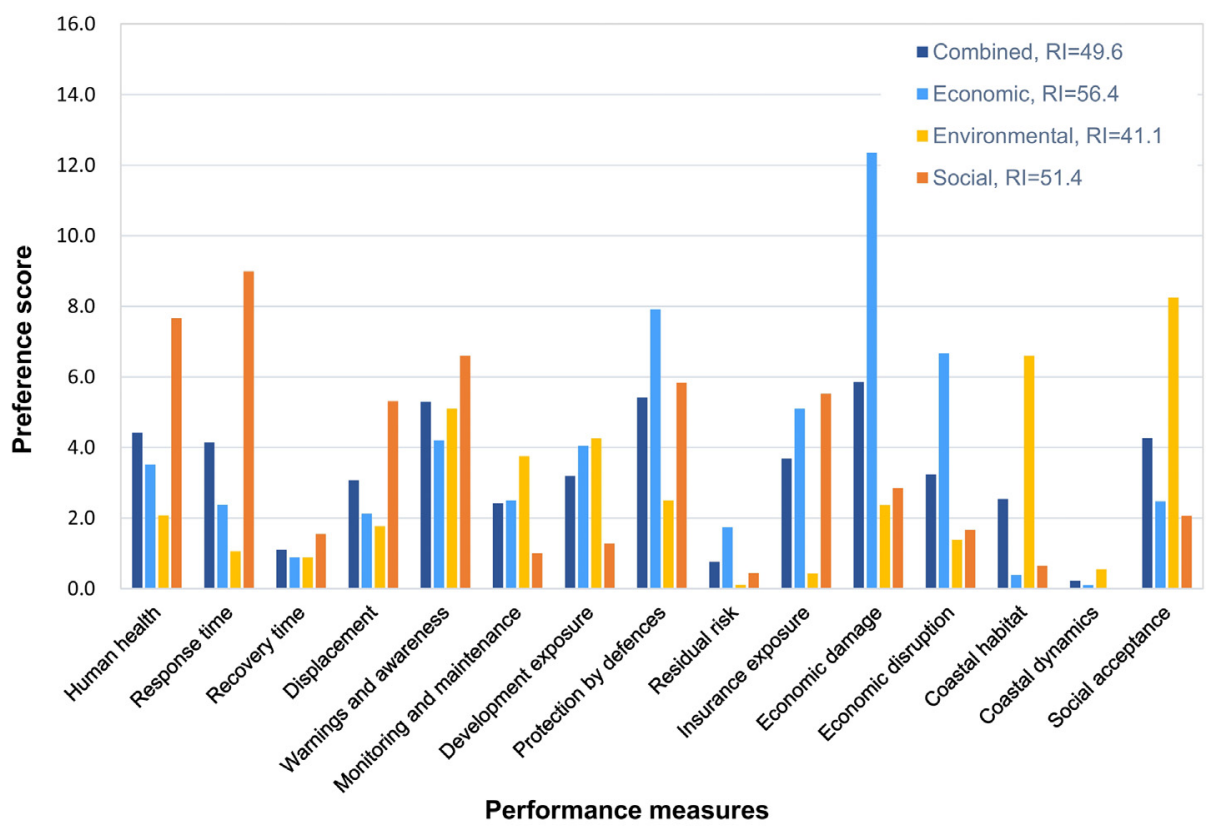

b)

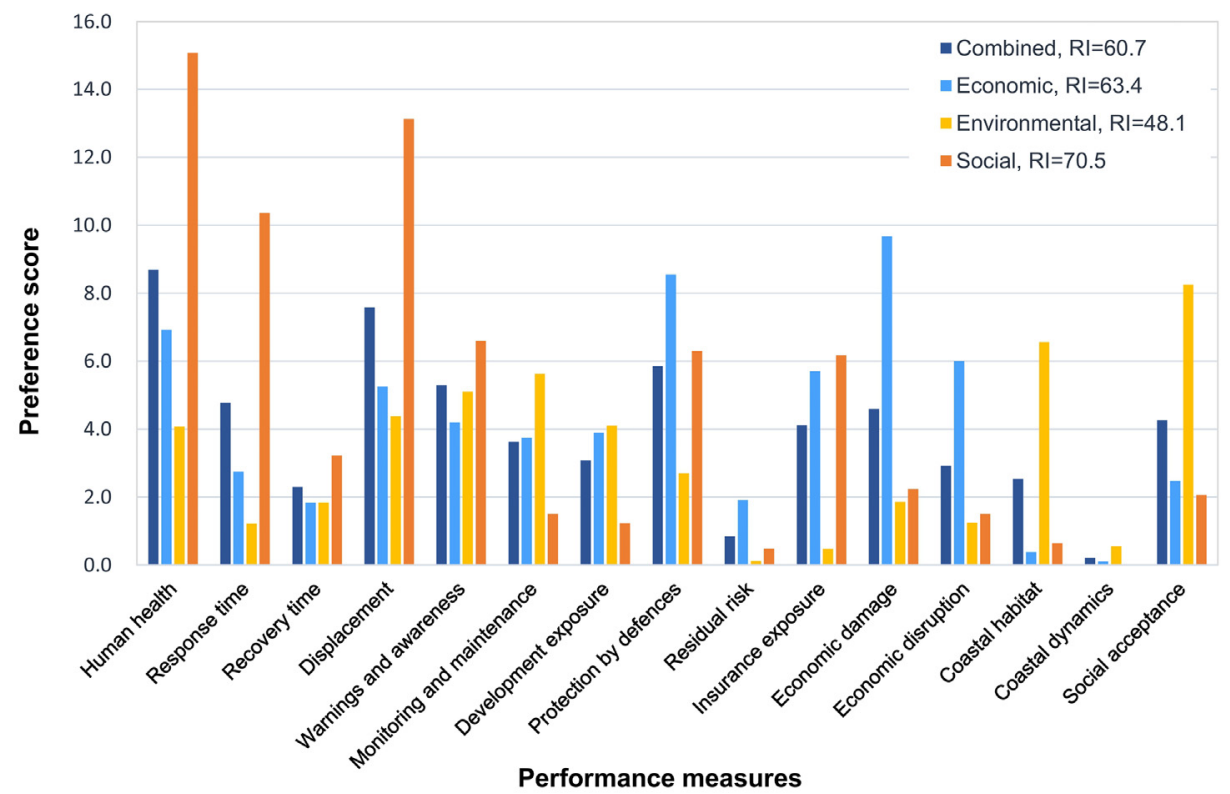

Fig. 7. 50-year projection for the preference scores of individual performance measures in Portsmouth for a) Pathway 1 ; b) Pathway 2. 


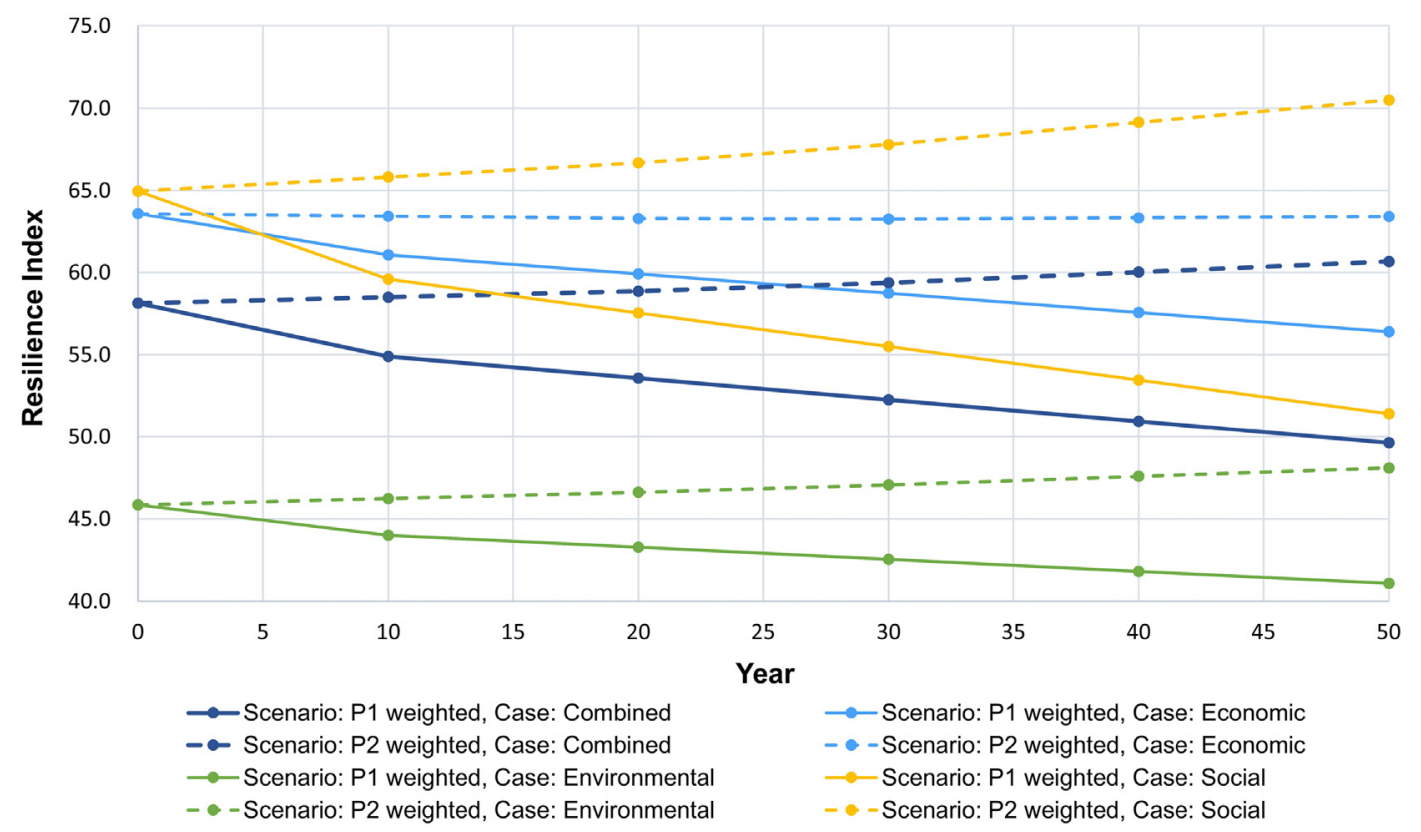

Fig. 8. Time evolution of the coastal Resilience Index for Portsmouth under two Pathways (P1 and P2).

Another emerging aspect of using adaptation pathways to deliver enhanced resilience, is the need to explore more radical changes and solutions and in particular any associated 'transitions' (e.g., changing from a defended to an undefended coast). In the pilot project we considered two types of transition: (i) directed (and generally relatively rapid) transitions, where the changes needed are known and can be planned; and (ii) progressive transitions (slower with greater uncertainty about the end point), where there is a need to explore options and work towards an acceptance within local communities. In some instances, this constitutes a form of 'wicked problem', where there are winners and losers, whatever solution is adopted. The CRM can inform the process and present the implications of different pathways in a transparent manner (including how this varies with different stakeholder perspectives).

\section{Conclusions}

The adoption of resilience as an overarching framework for strategic coastal hazard management has hitherto been limited, possibly due to the success of the prevailing risk-based management paradigm. As the extent of climate change impacts become apparent, higher levels of risk from flooding and erosion will either have to be tolerated, or communities will have to adapt. Resilience is a broader concept that incorporates risk, but goes beyond it to consider the ability to anticipate and cope with adverse events that will inevitably occur. The main challenge is to devise a rigorous framework for quantifying resilience, such that comparative geographical assessments and forward modelling of temporal changes and the effects of specific adaptation pathways become possible.

\section{a) Pathway 1}

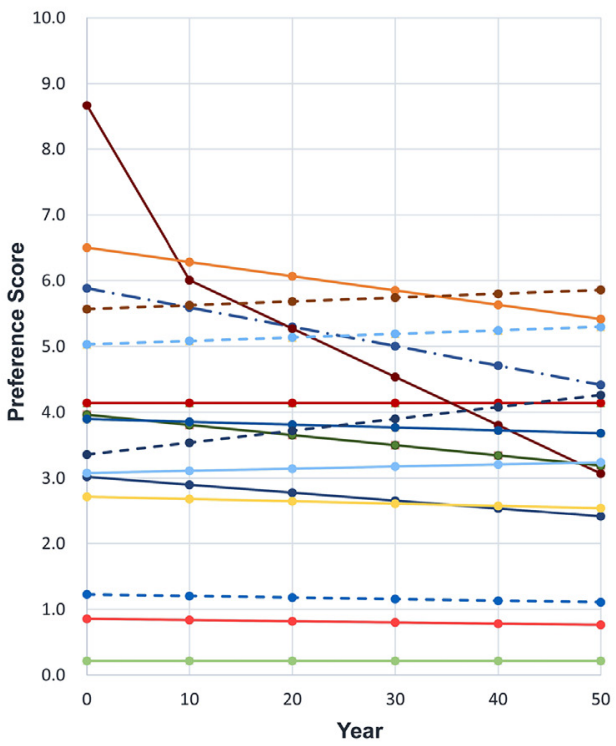

\section{b) Pathway 2}

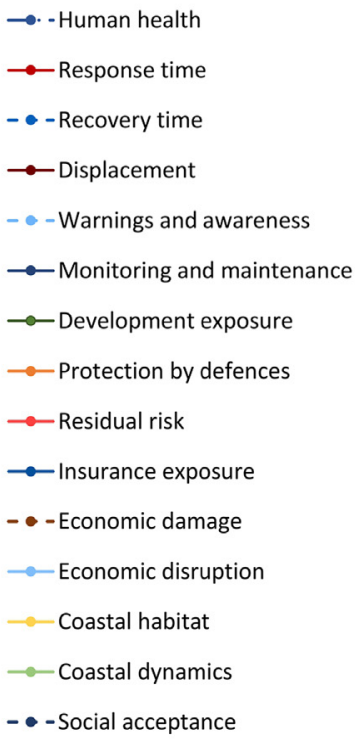

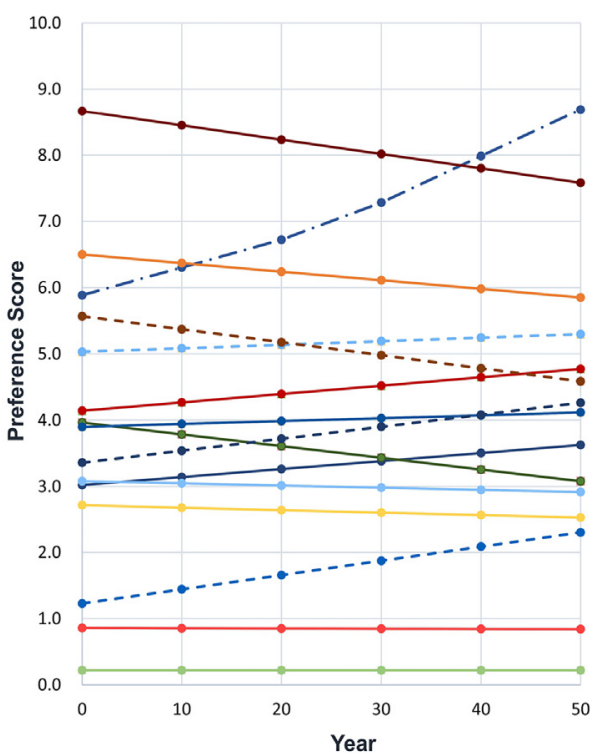

Fig. 9. Time evolution of the preference scores in Portsmouth under a) Pathway 1; b) Pathway 2. 

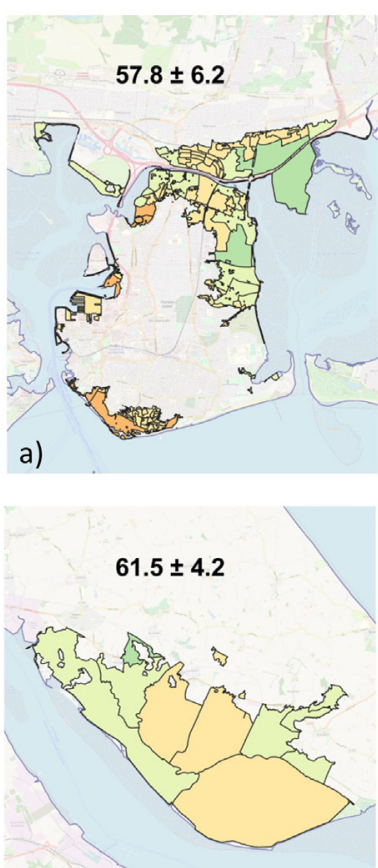

e)

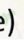

Fig. 10. Portsmouth and Humber Case Studies showing the Resilience Index for eac f) Environmental, (c and g) Economic, and ( $\mathrm{d}$ and h) Social perspectives on resilience.

In this paper, we adopt an existing definition of resilience (Rosati et al., 2015) and devise a model to quantify resilience that can support a decision-making framework with the overarching objective of enhancing the current state of coastal resilience. This is necessarily pragmatic but includes an explicit consideration of stakeholder preferences and a wider policy-making context that determines the purpose and potential beneficiaries (i.e., 'resilience against what?' and 'for whom?'). A set of existing indicators that quantify the economic, environmental and social dimensions of coastal resilience utilizing national open-access geospatial datasets are evaluated using Multiple-Criteria Analysis. The analysis integrates what are presently a disparate set of policy objectives, extending from the traditional engineered options associated with shoreline management planning to a broader perspective that also considers coastal community characteristics and priorities. A prototype model generates a system-wide Resilience Index that can be mapped spatially across a range of scales, as shown by illustrative case studies for Portsmouth and part of the Humber estuary at the local level, and a broader-scale analysis of the entirety of the English coastal flood and erosion hazard zone. We also show how, given appropriate hazard and socio-economic scenarios, time trajectories of coastal resilience can be modelled to reveal the impact of alternative adaptive pathways. Formalising coastal resilience depends on the context and goals and this will differ around the world. In some countries the legacy of coastal defences will dominate the debate (e.g., UK, North-West Europe in general), whereas elsewhere disaster risk management and recovery is the major consideration (e.g. USA and Bangladesh). Applying resilience in other coastal contexts is likely to identify further diversity, which could usefully be analysed to guide practise.

A shift from a predominantly risk-based to a broader resiliencebased approach for the management of coastal hazards requires a firm commitment from government to develop a consensus methodology, including agreement on the weightings of the component indicators. We advocate using these subjective weightings constructively to highlight the convergence/divergence that arises from differing stakeholder perspectives. Further, there is a need to establish the incentives for coastal managers to engage with and apply the approach proposed, particularly where the process or outcomes could be complex or have long lasting implications. Such incentives may be in the form of funding, but could also be changes in the law or powers delegated to the relevant authorities to enable them to take new courses of action. Such a policy transition to a less sectoral approach may also challenge existing governance arrangements in some countries and require more integration and inter-agency cooperation. The proposed coastal resilience framework, with the tools to support planning and measure progress, have the potential to help enable this transition.

\section{CRediT authorship contribution statement}

All authors contributed to Conceptualisation, Method development, Review and Editing of the paper; Data preparation was by Hill, Carpenter and Townend; Modelling was by Carpenter and Townend; and the paper was Drafted by French, Nicholls and Townend.

\section{Declaration of competing interest}

The authors declare that they have no known competing financial interests or personal relationships that could have appeared to influence the work reported in this paper.

\section{Acknowledgements}

This work was supported by the Strategic Priorities Fund, UK Climate Resilience Programme through a UK Research \& Innovation award NE/ S016651/1. Project partners included ABPmer, the Coastal Group Network, National trust, RSPB, Wildfowl and Wetlands Trust, National Flood Forum, Natural England and Network Rail. The East Solent Coastal Partnership and the Scarborough District Council hosted our regional workshops. We thank all the participants at our national and regional workshops. Susan Hanson helped prepare the figures, including drafting Figs. 2, 4 and 5. We are also grateful to the reviewers for the insights and suggestions they provided. 
a)

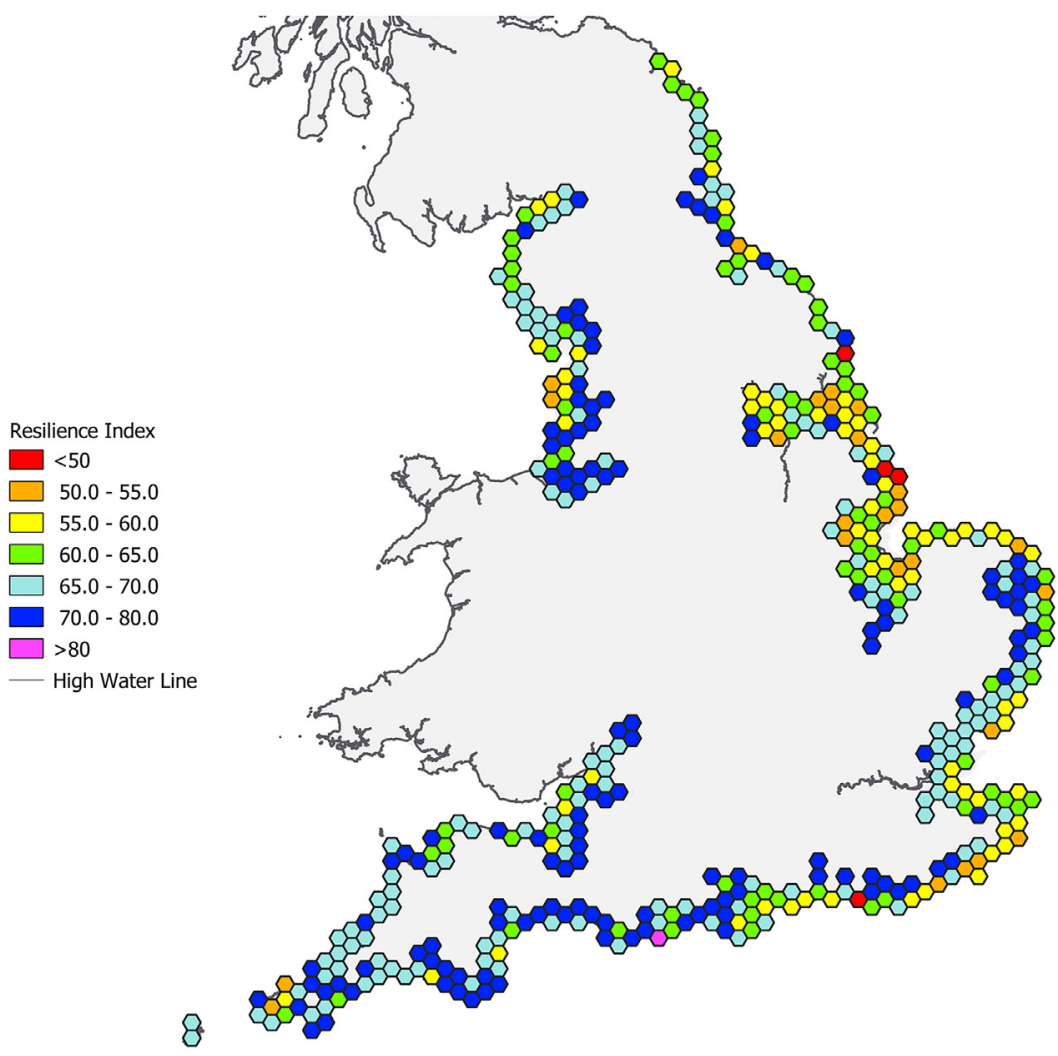

b)

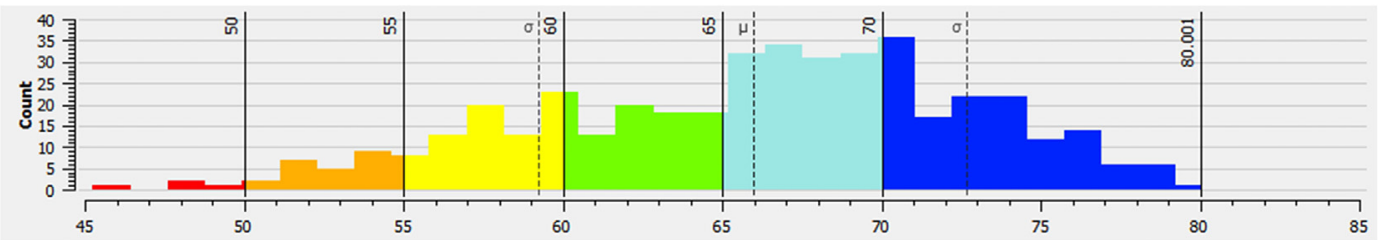

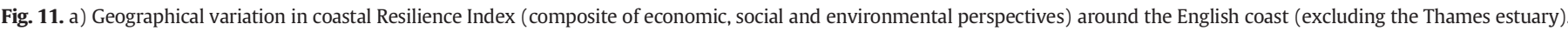
Hexagons are $90 \mathrm{~km}^{2}$ output areas. b) The distribution of $R I$ values.

\section{Appendix A. Supplementary information}

Supplementary data to this article can be found online at https://doi. org/10.1016/j.scitotenv.2021.146880.

\section{References}

Adger, W.N., 2000. Social and ecological resilience: are they related? Prog. Hum. Geogr. 24 (3), 347-364.

Adger, W.N., Hughes, T.P., Folk, C., Carpenter, S.R., Rockstrom, J., 2005. Social-ecological resilience to coastal disasters. Science 309, 1036-1039.

Alexander, D.E., 2013. Resilience and disaster risk reduction: an etymological journey. Nat. Hazards Earth Syst. Sci. 13, 2707-2716. https://doi.org/10.5194/nhess-132707-2013.

Barquet, K., Cumiskey, L., 2018. Using participatory Multi-Criteria Assessments for assessing disaster risk reduction measures. Coast. Eng. 134, 93-102.

Bernhardt, J.R., Leslie, H.M., 2013. Resilience to climate change in coastal marine ecosystems. Annu. Rev. Mar. Sci. 5, 371-392.

Bostick, T.P., Holzer, T.H., Sarkani, S., 2017. Enabling stakeholder involvement in coastal disaster resilience planning. Risk Anal. 37, 1181-1200. https://doi.org/10.1111/ risa.12737.

Brouwer, R., Van Ek, R., 2004. Integrated ecological, economic and social impact assessment of alternative flood control policies in the Netherlands. Ecol. Econ. 50, 1-21.

Brown, J.D., Morissey, K., Knight, P., Prime, T.D., Almeida, L.P., Masselink, G., Bird, C.O., Dodds, D., Plater, A.J., 2018. A coastal vulnerability assessment for planning climate resilient infrastructure. Ocean Coast. Manage. 163, 101-112.

Brown, K., Adger, N.W., Tompkins, E., Bacon, P., Shim, D., Young, K., 2001. Trade-off analysis for marine protected area management. Ecol. Econ. 37, 417-434.

Brown, S., Nicholls, R.J., Hanson, S.E., et al., 2014. Shifting perspectives on coastal impacts and adaptation. Nat. Clim. Chang. 4, 752-755. https://doi.org/10.1038/nclimate2344.
Burgess, J., Stirling, A., Clark, J., Davies, G., Eames, M., Staley, K., Williamson, S., 2007. Deliberative mapping: a novel analytic-deliberative methodology to support contested science-policy decisions. Publ. Understand. Sci. 16, 299-322.

Burton, I., 1996. The growth of adaptation capacity: practice and policy. In: Smith, J., Bhatti, N., Menzhulin, G., Benioff, R., Budyko, M.I., Campos, M., Jallow, B., Rijsberman, F. (Eds.), Adapting to Climate Change: An International Perspective. Springer-Verlag, New York.

Caffin, B.B., Scown, M., 2018. Social-ecological resilience and geomorphic systems. Geomorphology 305, 221-230. https://doi.org/10.1016/j.geomorph.2017.09.038.

Cai, H., Lam, N.S.N., Qiang, Y., Zou, L., Correll, R.M., Mihunov, V., 2014. A synthesis of disaster resilience measurement methods and indices. In. J. Disast. Risk Reduction 31, 844-855. https://doi.org/10.1016/j.ijdrr.2018.07.015.

Carpenter, S., Hill, C.T., 2020 Technical Report on Case Study and National Application of the CoastalRes Methodology, under the Strategic Priorities Fund: UK Climate Resilience programme funded by the Natural Environment Research Council (NERC) https://www.channelcoast.org/ccoresources/coastalres/.

Chambers, J.C., Allen, C.R., Cushman, S.A., 2019. Operationalizing ecological resilience concepts for managing species and ecosystems at risk. Front. Ecol. Evol. 12. https://doi. org/10.3389/fevo.2019.00241.

Christie, E.K., Spencer, T., Owen, D., Mclvor, A.L., Moller, I., Viavattene, C., 2018. Regional coastal flood risk assessment for a tidally dominant, natural coastal setting: North Norfolk, southern North Sea. Coast. Eng. 134, 177-190. https://doi.org/10.1016/j. coastaleng.2017.05.003.

Cimato, F., Mullan, M., 2010. Adapting to Climate Change: Analysing the Role of Government. Defra Evidence and Analysis Series Paper 1, Defra, 77pp. https://www.gov.uk/ government/publications/adapting-to-climate-change-analysing-the-role-of-government Last accessed 15 Feb 2021.

Cinelli, M., Coles, S.R., Kirwan, K., 2014. Analysis of the potentials of multi criteria decision analysis methods to conduct sustainability assessment. Ecol. Indic. 46, 138-148. https://doi.org/10.1016/j.ecolind.2014.06.011.

Climate Change Committee, 2018. Managing the coast in a changing climate. Committee on Climate Change, London, 70pp. https://www.theccc.org.uk/wp-content/uploads/ 2018/10/Managing-the-coast-in-a-changing-climate-October-2018-1.pdf Last accessed 15 Feb 2021. 
Cope, S., Bradbury, A., Gorczynska, M., McInnes, R., 2007. A Strategic Approach to Managing Mudflat and Saltmarsh Loss Across the North Solent. UK. In, Coastal Management, Thomas Telford, pp. 59-68.

DCLG, 2009. Multi-criteria Analysis: A Manual. 168pp. Department for Communities and Local Government, London. https://assets.publishing.service.gov.uk/government/uploads/system/uploads/attachment_data/file/7612/1132618.pdf Last accessed 15 Feb 2021.

DEFRA, 2012. Coastal Change Pathfinder Review: Final Report. Flood Management Team. Department for Environment, Food and Rural Affairs, London. Available at https://assets.publishing.service.gov.uk/government/uploads/system/uploads/attachment_ data/file/69508/pb13720-coastal-pathfinder-review.pdf Last accessed 15 Feb 2021.

DEFRA, 2015. Flood Resilience Community Pathfinder Evaluation Final Evaluation Report. Department for Environment, Food and Rural Affairs, London. Available at http:// randd.defra.gov.uk/Document.aspx?Document=13185_FD2664_

FloodResilienceCommunityPathfinderSchemeEvaluation_FR.pdf Last accessed 15 Feb 2021.

DEFRA, 2018. Adaptation to Coastal Change Quick Scoping Review. Flood Management Team. Department for Environment, Food and Rural Affairs, London.

EA, 2019. Draft National Flood and Coastal Erosion Risk Management Strategy for England. Environment Agency, 64pp. < https://consult.environment-agency.gov.uk/ fcrm/national-strategy-public/user_uploads/fcrm-strategy-draft-final-1-may-v0.13as-accessible-as-possible.pdf > , Last accessed 15 Feb 2021.

Estévez, R.A., Gelcich, S., 2015. Participative multi-criteria decision analysis in marine management and conservation: research progress and the challenge of integrating value judgements and uncertainty. Mar. Policy 61, 1-7.

Fekete, A., Hartmann, T., Jüpner, R., 2019. Resilience: on-going wave or subsiding trend in flood risk research and practice? WIREs Water. 2020;7:e1397. doi:https://doi.org/ $10.1002 /$ wat2.1397.

Fisher, K. and Goodliffe, R., 2020. Adaptive coastal management at three sites in East Anglia. In: Proceedings Coastal Management 2019. ICE, London, pp. 245-258.

French, J.R., 2006. Tidal marsh sedimentation and resilience to environmental change: exploratory modelling of tidal, sea-level and sediment supply forcing in predominantly allochthonous systems. Mar. Geol. 235, 119-136.

Garmendia, E., Gamboa, G., Franco, J., Garmendia, J.M., Liria, P., Olazabal, M., 2010. Social multi-criteria evaluation as a decision support tool for integrated coastal zone management. Ocean Coast. Manage. 53 (7), 385-403.

Gerard, R.E.C., 2017. Developing annex of community competence in flood response for flood-affected rural parishes on the Somerset Levels and Moors using composite and spatial datasets. Area 50, 344-352. https://doi.org/10.1111/area12416.

Grafton, R.Q., Doyen, L., Béné, C., Borgomeo, E., Brooks, K., Chu, L., Cumming, G.S., Dixon, J., Dovers, S., Garrick, D., Helfgott, A., Jiang Q. Katic, P., Kompas, T., Little, L.R., Matthews, N., Ringler, C., Squires, D., Steinshamn, S.I., Villasante, S., Wheeler, S., Williams, J., Wyrwoll, P.R., 2019. Realizing resilience for decision-making. Nature Sustainability 2 (10), 907-913. https://doi.org/10.1038/s41893-019-0376-1.

Haasnoot, M., Kwakkel, J.H., Walker, W.E., ter Maat, J., 2013. Dynamic adaptive policy pathways: A method for crafting robust decisions for a deeply uncertain world. Glob. Environ. Chang. 23 (2), 485-498. https://doi.org/10.1016/j. gloenvcha.2012.12.006.

Haasnoot, M., van't Klooster, S., van Alphen, J., 2018. Designing a monitoring system to detect signals to adapt to uncertain climate change. Glob. Environ. Chang. 52, 273-285. https://doi.org/10.1016/j.gloenvcha.2018.08.003.

Haigh, I., Nicholls, R. and Wells, N., 2011. Rising sea levels in the English Channel 1900 to 2100. Proceedings of the Institution of Civil Engineers - Maritime Engineering, 164, 81-92. doi:https://doi.org/10.1680/maen.2011.164.2.81.

Haigh, I.D., Nicholls, R.J., Penning-Roswell, E. and Sayers, P. (2020) Impacts of climate change on coastal flooding, relevant to the coastal and marine environment around the UK. MCCIP Science Review 2020, 546-565. doi: 10.14465/2020.arc23.cfl.

Haimes, Y.Y., 2009. On the definition of resilience in systems. Risk Anal. 29 (4), 498-501.

Hajkowicz, S., 2008. Supporting multi-stakeholder environmental decisions. J. Environ. Manag. 88, 607-614.

Hall, J.W., Harvey, H., Manning, L.J., 2019. Adaptation thresholds and pathways for tidal flood risk management in London. Clim. Risk Manag. 24, 42-58. https://doi.org/ 10.1016/j.crm.2019.04.001.

HMG, 2016. National Flood Resilience Review, p. 141 HM Government. https://assets. publishing.service.gov.uk/government/uploads/system/uploads/attachment_data/ file/551137/national-flood-resilience-review.pdf.

Holling, C.S., 1973. Resilience and stability of ecological systems. Ann. Rev. Ecol. Syst. 4, 1-23. https://doi.org/10.1146/annurev.es.04.110173.000245.

Houser, C., Wernette, P., Rentschlar, E., Jones, H., Hammond, B., Trimble, S., 2015. Poststorm beach and dune recovery: implications for barrier island resilience. Geomorphology 234, 56-63

Hummel, M.A., Wood, N.J., Schweikert, A., et al., 2018. Clusters of community exposure to coastal flooding hazards based on storm and sea level rise scenarios-implications for adaptation networks in the San Francisco Bay region. Reg. Environ. Chang. 18, 1343-1355. https://doi.org/10.1007/s10113-017-1267-5.

Keeney, R.L., Raiffa, H., 1976. Decisions With Multiple Objectives: Preferences and Value Tradeoffs. John Wiley and Sons, 569pp.

Kim, H., Marcouiller, D.W., 2020. Making sense of resilience planning and policy in the pursuit of sustainable development and disaster risk reduction. Clim. Dev. 12 (3), 228-240. https://doi.org/10.1080/17565529.2019.1613215.

Kim, H., Woosnam, K.M., Aleshinloye, K.D., 2014. Evaluating coastal resilience and disaster response: the case of Galveston and Texas gulf counties following Hurricane Ike. Coast. Manag. 42, 227-245. https://doi.org/10.1080/08920753.2014.904188.

Kim, Y., Eisenberg, D.A., Bondak, E.N., 2017. Fail-safe and safe-to-fail adaptation: decisionmaking for urban flooding under climate change. Clim. Chang. 145, 397-412. https:// doi.org/10.1007/s10584-017-2090-1.
Kingsborough, A., Borgomeo, E., Hall, J.W., 2016. Adaptation pathways in practice: mapping options and trade-offs for London's water resources. Sustain. Cities Soc. 27, 386-397. https://doi.org/10.1016/j.scs.2016.08.013.

Klein, R.J.T., Smit, M.J., Goosen, H., Hulsbergen, C.H., 1998. Resilience and vulnerability: coastal dynamics or Dutch dikes? Geogr. J. 164, 259-268.

Klein, R.J.T., Nicholls, R.J., Thomalla, F., 2003. Resilience to natural hazards: how useful is this concept? Glob. Environ. Chang. B Environ. Hazards 5, 35-45.

Kombiadou, K., Costas, S., Carrasco, A.R., Plomaritis, T.A., Ferreira, O., Matias, A., 2019 Bridging the gap between resilience and geomorphology of complex coastal systems. Earth Sci. Rev. 198, 19.

Kress, M.M., Touzinsky, K.F., Vuxton, E.A., Greenfield, B., Lillycrop, L.S., Rosati, J.D., 2016 Alignment of U. S. ACE civil works missions to restore habitat and increase environmental resiliency. Coastal Management 44 (3), 193-208. https://doi.org/10.1080/ 08920753.2016.1160203.

Lawrence, J., Bell, R., Stroombergen, A., 2019. A hybrid process to address uncertainty and changing climate risk in coastal areas using dynamic adaptive pathways planning, multi-criteria decision analysis \& real options analysis: a New Zealand application. Sustainability 11 (2). https://doi.org/10.3390/su11020406.

Lazarus E D, Aldabet S, Thompson C E L, Hill C T, Nicholls R, French J, Brown S, Tompkins E L, Haigh I, Townend I H and Penning-Rowsell E, 2020, The UK needs an open-data portal dedicated to coastal flood and erosion hazard risk and resilience, EarthArXiv, doi:10.31223/X5989C.

Le Cozannet, G., Rohmer, J., Cazenave, A., Idier, D., van de Wal, R., de Winter, R., Pedreros, R., Balouin, Y., Vinchon, C., Oliveros, C., 2015. Evaluating uncertainties of future marine flooding occurrence as sea-level rises. Environ. Model Softw. 73, 44-56. https://doi.org/10.1016/j.envsoft.2015.07.021.

Levy, J.K., 2005. Multiple criteria decision making and decision support systems for flood risk management. Stoch. Environ. Res. Risk Assess. 19, 438-447. https://doi.org/ 10.1007/s00477-005-0009-2.

Linkov, I., Eisenberg, D.A., Bates, M.E., Chang, D., Convertino, M., Allen, J.H, Flynn, S.E., Seager, T.P., 2013. Measurable resilience for actionable policy. Environ. Sci. Technol. 47:10103-10110. doi: https://doi.org/10.1021/es403443n.

Linkov, I., Bridges, T., Creutzig, F., Decker, J., Fox-Lent, C., Kröger, W., Lambert, J., Levermann, A., Montreuil, B., Nathwani, J., Nyer, R., Renn, O., Scharte, B., Scheffler, A., Schreurs, M., Thiel-Clemen, T., 2014. Changing the resilience paradigm. Natur. Clim. Change 4 (6), 407-409.

Lumbroso, D., Ramsbottom, D., 2018. Flood Risk Management in the United Kingdom. Resilience, Series, In, pp. 79-87 https://doi.org/10.1016/b978-0-12-811891-7.00006-2.

Marchau V A W J, Walker W E, Bloemen P J T M and Popper S W (eds), 2019, Decision Making Under Deep Uncertainty. p. 405, Springer, doi:https://doi.org/10.1007/9783-030-05252-2.

Masselink, G., Lazarus, E.D., 2019. Defining coastal resilience. Water 11, 2587. https://doi. org/10.3390/w11122587.

Masselink, G., Russell, P., Rennie, A., Brooks, S. and Spencer, T. (2020) Impacts of climate change on coastal geomorphology and coastal erosion relevant to the coastal and marine environment around the UK. MCCIP Science Review 2020, 158-189. doi: 10.14465/2020.arc08.cgm.

Nicholls, R.J., Townend, I.H., Bradbury, A.P., Ramsbottom, D., Day, S.A., 2013. Planning for long-term coastal change: experiences from England and Wales. Ocean Eng. 71, 3-16. https://doi.org/10.1016/j.oceaneng.2013.01.025.

Office for National Statistics, 2012. In: Tait, A. (Ed.), Changes to Output Areas and Super Output Areas in England and Wales, 2001 to 2011, 2012 Available at: https://data. gov.uk/dataset/f6f41c6b-4f8d-441e-9efc-bc665ed090a0/changes-to-output-areasand-super-output-areas-in-england-and-wales-2001-to-2011.

Oppenheimer, M., B.C. Glavovic, J. Hinkel, R. van de Wal, A.K. Magnan, A. Abd-Elgawad, R. Cai, M. CifuentesJara, R.M. DeConto, T. Ghosh, J. Hay, F. Isla, B. Marzeion, B. Meyssignac, and Z. Sebesvari, 2019: Sea level rise and implications for low-lying islands, coasts and communities. In: IPCC Special Report on the Ocean and Cryosphere in a Changing Climate [H.-O. Pörtner, D.C. Roberts, V. Masson-Delmotte, P. Zhai, M. Tignor, E. Poloczanska, K. Mintenbeck, A. Alegría, M. Nicolai, A. Okem, J. Petzold, B. Rama, N.M. Weyer (eds.)]. In press.

Orford, J.D., Anthony, E.J., 2011. Extreme events and the morphodynamics of graveldominated coastal barriers: strengthening uncertain ground. Mar. Geol. 290, 41-45.

Park, J., Seager, T.P., Rao, P.S.C., Convertino, M., Linkov, I., 2013. Integrating risk and resilience approaches into catastrophe management in engineering systems. Risk Anal. 33 (3), 356-368.

Paton, D., Smith, L., Violanti, J., 2000. Disaster response: risk, vulnerability and resilience. Disaster Prev. Manag. 9 (3), 173-180.

Piégay, H., Chabot, A., Le Lay, Y.F., 2018. Some comments about resilience: from cyclicity to trajectory, a shift in living and non-living system theory. Geomorphology https:// doi.org/10.1016/j.geomorph.2018.09.018.

Pimm, S.L., 1991. The Balance of Nature? Ecological Issues in the Conservation of Species and Communities. Univ, Chicago Press.

Pimm, S.L., Donohue, I., Montoya, J.M., Loreau, M., 2019. Measuring resilience is essential to understand it. Nature Sustainability 2, 895-897. https://doi.org/10.1038/s41893019-0399-7.

Ramieri, H.A., Barbanti, A., Santos, F.D., Gomes, A., Hilden, M., Laihonen, P., Marinova, N., Santini, M., 2011. Methods for Assessing Coastal Vulnerability to Climate Change. ETC CCA Technical Paper, Bologna (IT).

Ranger, N., Reeder, T., Lowe, J., 2013. Addressing ‘deep’ uncertainty over long-term climate in major infrastructure projects: four innovations of the Thames Estuary 2100 Project. EURO J. Decis. Process. 1, 233-262. https://doi.org/10.1007/s40070-0130014-5.

Raymond, C.M., Fazey, I., Reed, M.S., Stringer, L.C., Robinson, G.M., Evely, A.C., 2010. Integrating local and scientific knowledge for environmental management. J. Environ. Manag. 91, 1766-1777. 
Rittel, H.W.J., Webber, M.M., 1973. Dilemmas in a general theory of planning. Policy. Sci. 4, $155-169$.

Rosati, J.D., Touzinsky, K.F., Lillycrop, W.J., 2015. Quantifying coastal system resilience for the US Army Corps of Engineers. Environ Syst Decis https://doi.org/10.1007/s10669015-9548-3.

Roy, B., 1968. Classement et choix en presence de points de vue multiples (la methode Electre). Revue Francaise de d'Informatique et de Recherche Operationnelle 8, 57-75.

Rumson, A.G. Hallett, S.H 2019. Innovations in the use of data facilitating insurance as a resilience mechanism for coastal flood risk. Sci. Total Environ. 661, 598-612. https:// doi.org/10.1016/j.scitotenv.2019.01.114

Rumson, A.G., Payo, A., Hallett, S.H., 2020. The role of data within coastal resilience assessments: an East Anglia, UK, case study. Ocean Coast. Manage. 185. https://doi.org/ 10.1016/j.ocecoaman.2019.105004

Saaty, T., 1980. The Analytical Hierarchy Process. John Wiley, New York.

Sahr, K., White, D., Kimerling, A.J., 2003. Geodesic discrete global grid systems. Cartog. Geogr. Info. Sci. 30 (2), 121-134.

Sanderson, E.W., Solecki, W.D., Waldman, J.R., Parris, A.S. (Eds.), 2016. Prospects for Resilience: Insights from New York City's Jamaica Bay. Press, Island.

Sanuy, M., Jiménez, J.A., Plant, N., 2020. A Bayesian Network methodology for coastal hazard assessments on a regional scale. the BN-CRAF. Coastal Engineering 157. https:// doi.org/10.1016/j.coastaleng.2019.103627.

Sekovski, I., Del Rio, L., Armaroli, C., 2020. Development of a coastal vulnerability index using analytical hierarchy process and application to Ravenna province (Italy). Ocean Coast. Manage. 183, 104982. https://doi.org/10.1016/j. ocecoaman.2019.104982.

Shamaskin, A., Samiappan, S., Liu, J., Roberts, J., Linhoss, A., Evans, K., 2020. Multi-attribute ecological and socioeconomic geodatabase for the Gulf of Mexico coastal region of the United States. Data 5, 3. https://doi.org/10.3390/data5010003.

Shaxson, L., 2005. Is your evidence robust enough? Questions for policy makers and practitioners. Evidence \& Policy: A Journal of Research, Debate and Practice 1 (1), 101-112. https://doi.org/10.1332/1744264052703177.

Sheaves, M., Sporne, I., Dichmont, C.M., Bustamante, R., Dale, P., Deng, R., Dutra, L.X.C., van Putten, I., Savina-Rollan, M., Swinbourne, A., 2016. Principles for operationalizing climate change adaptation strategies to support the resilience of estuarine and coastal ecosystems: an Australian perspective. Mar. Policy 8, 229-240. https://doi.org/ 10.1016/j.marpol.2016.03.014.

Sidle, R.C., Benson, W.H., Carriger, J.F., Kamai, T., 2013. Broader perspective on ecosystem sustainability: consequences for decision making. Proc. Nat. Acad, Sci www.pnas.org/ cgi/doi/10.1073/pnas.1302328110.

Stephens, S., Bell, R., Lawrence, J., 2017. Applying principles of uncertainty within coastal hazard assessments to better support coastal adaptation. Journal of Marine Science and Engineering 5 (3). https://doi.org/10.3390/jmse5030040.
Stephens, S.A., Bell, R.G., Lawrence, J., 2018. Developing signals to trigger adaptation to sea-level rise. Environ. Res. Lett. 13 (10). https://doi.org/10.1088/1748-9326/aadf96.

Stevens, A.J., Clarke, D., Nicholls, R.J., Wadey, M.P., 2015. Estimating the long-term historic evolution of exposure to flooding of coastal populations. Natural Hazards and Earth System Sciences Discussions 3 (2), 1681-1715.

Thorne, C.R., Evans, E.P., Penning-Rowsell, E.C., 2007. Future Flooding and Coastal Erosion Risks. Thomas Telford, London.

Thorne, K.M., et al., 2015. Collaborative decision-analytic framework to maximize resilience of tidal marshes to climate change. Ecol. Soc. 20 (1), 30. https://doi.org/ 10.5751/ES-07018-200130.

Townend, I.H., French, J.R., Nicholls, R.J., Brown, S., Carpenter, S., Haigh, I.D., Hill, C.T., Lazarus, E., Penning-Rowsell, E.C., Thompson, C., Tompkins, E., 2020, CoastalRes Final Report, under the Strategic Priorities Fund: UK Climate Resilience programme funded by the Natural Environment Research Council (NERC). https://www.channelcoast. org/ccoresources/coastalres/.

Turner, R.K., et al., 2007. A cost-benefit appraisal of coastal managed realignment policy. Glob. Environ. Chang. 17, 397-407. https://doi.org/10.1016/j.gloenvcha.2007.05.006.

U.S. Army Corps of Engineers (USACE), 2014. From flood damage reduction to flood risk management: implications for U.S. Army Corps of Engineers policy and programs. 2014-R-02. Institute for Water Resources, U.S. Army Corps of Engineers, Washington, DC, pp 1-63. https://www.iwr.usace.army.mil/Portals/70/docs/iwrreports/ 2014-R-02.pdf Last accessed 15 Feb 2021.

Viavattene, C., Jimenez, J.A., Ferreira, O., Priest, S., Owen, D., McCall, R., 2018. Selecting coastal hotspots to storm impacts at the regional scale: a coastal risk assessment framework. Coast. Eng. 134, 33-47. https://doi.org/10.1016/j.coastaleng.2017.09.002.

Wadey, M.P., Nicholls, R.J., Hutton, C., 2012. Coastal flooding in the Solent: an integrated analysis of defences and inundation. Water 4, 430-459.

Walker, B., Salt, D., 2006. Resilience Thinking: Sustaining Ecosystems and People in a Changing World. Island Press, Washington, DC.

Walker, W.E., Haasnoot, M., Kwakkel, J.H., 2013. Adapt or perish: a review of planning approaches for adaptation under deep uncertainty. Sustainability 5, 955-979. https:// doi.org/10.3390/su5030955.

Willows R and Connell R, 2003, Climate adaptation: risk, uncertainty and decisionmaking, UKCIP Technical Report, pp. 1-154, Oxford.

Winn, P.J.S., Young, R.M., Edwards, A.M.C., 2003. Planning for the rising tides: the Humber Estuary Shoreline Management Plan. Sci. Total Environ. 314-316, 13-30. https://doi. org/10.1016/S0048-9697(03)00092-5. 